\title{
MODALIDAD APELATIVA Y GRAMATICALIZACIÓN EN EL DISCURSO: EL CASO DE NO ME DIGAS
}

\author{
FranCISCO JAVIER GRANDE Alija \\ Universidad de León \\ fjgraa@unileon.es
}

\begin{abstract}
Resumen
Basándonos principalmente en los datos suministrados por el Corpus de Referencia del Español Actual (CREA), se identifican y describen los usos discursivos que la forma apelativa no me digas presenta en la sincronía actual del español. El análisis de estos usos comunicativos pone de relieve que no me digas ha desarrollado diversos valores formulísticos que, no obstante, se pueden explicar desde las propiedades formales y semánticas originales de la expresión apelativa. Los diferentes grados de fijación e idiomaticidad que presentan estos valores formulísticos sugieren la existencia de varios grados de gramaticalización en el discurso, así como de un paso gradual en el "desplazamiento modal" o cambio por el que la modalidad expresada en el discurso acaba imponiéndose a la modalidad codificada. Como consecuencia de estos cambios, se ha producido una evolución desde la modalidad apelativa original a otros valores modales de carácter expresivo, epistémico y asertivo, así como su transformación en diversos marcadores discursivos de naturaleza modal.
\end{abstract}

PALABRAS CLAVE: modalidad apelativa, desplazamiento modal, gramaticalización, fijación e idiomaticidad.

\begin{abstract}
Based mainly on data supplied by the Corpus de Referencia del Español Actual (CREA), we have identified and described the synchronic discursive uses of the Spanish appellative form no me digas. The analysis of these communicative uses shows that this form is developing different formulistic values that, however, are related to the formal and semantic properties of no me digas. The varying degrees of fixedness and idiomaticity of these formulistic values point toward the existence of a continuum in the grammaticalization process, as well as the gradual adjustment in the "modal shift", moving from the original appellative modality to the modality expressed in discourse. As result of this, appellative modality has been replaced by other modal values of expressive, epistemic or assertive nature. Such semantic evolution is reflected in the transformation of various discourse markers of modal meaning.
\end{abstract}

KEY WORDS: appellative modality, modal shift, grammaticalization, fixedness and idiomaticity.

\section{Introducción}

El punto de partida de este trabajo se encuentra en nuestro interés por la modalidad apelativa y sus realizaciones discursivas. Dentro de este marco, se aborda el análisis de un conjunto de expresiones que tienen en común los siguientes rasgos formales básicos: 
verbo decir, modalidad apelativa, segunda persona del singular del presente de subjuntivo y presencia de la negación. Dicho de otra manera, todas se caracterizan por incluir la forma verbal no me digas (y variantes) en su estructura sintagmática. Aunque el punto de partida es semasiológico (nos ceñimos a ciertos requisitos formales), el objetivo último es ver cómo se resuelven discursivamente, es decir, dar cuenta de los diferentes valores comunicativos que asumen los enunciados en los que aparece dicha forma verbal. Se trata de considerar cómo contribuyen a la gestión y desarrollo del propio discurso en el que aparecen, de modo que la perspectiva que se adopta podría caracterizarse como "metadiscursiva".

El análisis de estos usos de la forma no me digas nos va a permitir centrar nuestra atención en dos cuestiones básicas:

- cómo a la modalidad apelativa original se van sumando otras modalizaciones suplementarias que, en algunos casos, pueden llegar a desbancarla;

- cómo esa forma verbal apelativa ha pasado a integrarse en ciertas rutinas discursivas que han acabado por condicionar sus características formales y semánticas (se tendrá que hablar de fijación e idiomaticidad como parte de un proceso gradual y progresivo de gramaticalización ${ }^{2}$ ).

El caso de no me digas es un ejemplo más de la marcada tendencia que las formas apelativas del verbo decir (dime, di que sí, y que lo digas, dímelo a mí, no digamos, no se diga, digamos, que digamos, que diga, di que... $)^{3}$ tienen a convertirse en procedimientos que ayudan a gestionar el discurso en alguno de sus múltiples aspectos (interactivos, modales, de formulación, de valoración expresiva, de intensificación....) y a transformarse en medios de expresión de naturaleza gramatical.

Sin olvidarnos, por supuesto, de las tendencias generales que hay detrás de este cambio, hay dos características particulares que parecen favorecer la evolución de esas formas verbales hacia el terreno señalado:

\footnotetext{
${ }^{1}$ En esta orientación metadiscursiva no me digas apunta al propio acto de enunciación en el que aparece, no a otro distinto. Compárense estos ejemplos: Juan, no me digas, es un poco retraído y Mañana cuando me veas no me digas nada hasta que te lo indique.

${ }^{2}$ Debe quedar claro que en ninguno de los casos que se van a estudiar ha culminado por completo el proceso de gramaticalización: en todos ellos todavía es posible introducir en el verbo variaciones relacionadas con el tratamiento de respeto.

${ }^{3}$ Un análisis de los usos metadiscursivos de estas formas apelativas puede encontrarse en Fernández Bernárdez (2002) y también, aunque ciñéndose a las formas apelativas de primera persona del plural, en Grande Alija (2010).
} 
- El significado léxico del verbo en que se basan esas expresiones apunta al acto de enunciación que da lugar a la creación de un discurso y, en concreto, a la del propio discurso en el que se integran esas formas verbales. Se desarrolla así una orientación metadiscursiva, es decir, una mirada interna del discurso a su enunciación.

- La naturaleza interactiva de la modalidad apelativa: el hablante intenta influir de algún modo sobre el oyente o destinatario, se dirige a él de una manera directa y explícita mediante marcas gramaticales específicas. Las formas apelativas tienen, pues, algo de llamada de atención, y ello favorece que tiendan a convertirse en procedimientos que alertan al destinatario sobre el desarrollo de las operaciones enunciativas, modales y expresivas que culminan en la creación de un discurso.

Nuestra exposición que, como ya se ha indicado, se ciñe al estudio de los valores discursivos de no me digas, se va a desarrollar conforme al siguiente esquema: en primer lugar, nos detendremos en el análisis de algunas características que presenta la forma apelativa que sirve de base a todos esos usos $(\$ 2$.$) ; a continuación (\$ 3$.$) , nos referire-$ mos a los tipos principales de unidades fraseológicas y a sus propiedades fundamentales (fijación, idiomaticidad...) con el objetivo de entender mejor la evolución formal y semántica de no me digas; seguidamente, se hará un análisis de los valores comunicativos que adquiere la mencionada expresión en el discurso, análisis que se organizará en dos orientaciones: retrospectiva ( $\$ 4.1$.) y prospectiva $(\$ 4.2$.); finalmente $(\$ 5$.), se abordarán los cambios formales y semánticos que se aprecian en los valores discursivos de no me digas desde la perspectiva de la teoría de la gramaticalización incidiendo especialmente en la importancia de los factores pragmáticos y en la aparición de nuevos valores modales. El trabajo se cierra con unas conclusiones en las que se resumen los aspectos más importantes tratados en el mismo.

\section{El punto de partida: no me digas como forma apelativa de carácter negativo}

\subsection{Algunas propiedades generales}

Centrándonos ya en las expresiones verbales apelativas cuyo estudio es el objetivo específico de este trabajo, destacan las siguientes características generales:

- Incorporan una referencia enunciativa en la que aparecen reflejados los componentes básicos de cualquier acto de enunciación:

- El acto mismo de enunciación (verbo decir).

- El sujeto o responsable de enunciación, que coincide referencialmente con el complemento del verbo (me). 
- El destinatario de la enunciación, que comparte referencia con el morfema de persona del verbo ( $2^{\mathrm{a}}$ persona del singular).

- Y, finalmente, el resultado o producto del acto de enunciación, al que se puede apuntar ya sea de forma explícita (por medio de un pronombre, un sintagma nominal o algún tipo de estructura proposicional) o de un modo implícito apoyándose en el contexto verbal.

- La presencia de la negación.

- La existencia de una dimensión asertiva: al utilizar esta expresión el hablante toma en consideración la verdad de un hecho para aceptarla o rechazarla.

\subsection{Comportamiento de la negación}

En lo que se refiere a la negación, su aparición suele ir ligada a un contexto previo que se pretende contradecir. Es lo que a veces se ha caracterizado como la naturaleza polémica de la negación (Ducrot, 1986): se utiliza un enunciado negativo porque en el contexto en el que se produce el acto de discurso parece prevalecer la información contraria, que es precisamente la que el locutor o responsable de la enunciación desea rechazar. Es decir, se plantea un enunciado negativo porque se supone que hay buenas razones para hacerlo, de lo contrario, desde un punto de vista informativo, resultaría irrelevante.

Con relación a las apelaciones negativas que aparecen en las fórmulas con no me digas, tendríamos, al menos en origen, dos contextos de uso distintos ${ }^{4}$ :

- Se trata de impedir que se verifique una circunstancia que ya se ha dado o se está dando. Se mira hacia atrás, hacia algo que ya ha pasado o está pasando. En el caso concreto de no me digas, se estaría intentando cesar el acto de habla que en ese momento estaría realizando el interlocutor, o bien, en caso de que ya se hubiera cumplido, de rechazarlo para que no se vuelva a producir.

- Se quiere evitar la realización de algo que, aunque todavía no es una realidad, podría verificarse en un futuro más o menos cercano, dado que existen indicios que así parecen indicarlo. Tiene una orientación clara hacia el futuro: se anticipa algo que todavía no es. En el caso de no me digas, se intentaría impedir un acto de enunciación futuro que sólo es una mera posibilidad.

Ciertamente, lo dicho se refiere al valor que estas formas apelativas negativas con $n o$ me digas tuvieron en su origen, y que todavía pervive plenamente en los usos menos

\footnotetext{
${ }^{4}$ Para el comportamiento semántico de las apelaciones negativas puede consultarse Haverkate (1979: 39) y Grande Alija (2002: 286-288).
} 
fosilizados. En los casos sometidos a un mayor grado de fijación e idiomaticidad, en los que el sentido apelativo ya está prácticamente perdido, no parece viable tal distinción. Sin embargo, creemos que todos ellos pueden organizarse en dos orientaciones básicas que, de algún modo, son una continuación de los dos tipos de apelaciones negativas señalados.

En efecto, de un lado, nos encontramos con usos que se caracterizan por implicar una reacción ante lo que el interlocutor acaba de decir. Suponen una mirada hacia atrás, en particular, hacia el discurso ya producido. Asumen, pues, una orientación que podríamos llamar retrospectiva. Por su propia naturaleza, estas fórmulas son típicas de la conversación y de una unidad como el intercambio ${ }^{5}$. De otro, aparecen ciertos usos que se orientan hacia el futuro, en concreto, hacia el que podría ser el potencial discurso futuro del oyente. Presentan una orientación que se podría denominar prospectiva.

Nuestro estudio se va a organizar en torno a estas dos orientaciones básicas que, sin embargo, han de tomarse más bien como una guía para facilitar el desarrollo de la exposición, puesto que no siempre es fácil establecer una frontera clara entre las dos perspectivas señaladas y a veces parece más adecuado hablar de un paso gradual entre ellas.

\subsection{Los contenidos asertivos implicados}

Con respecto a la dimensión asertiva a la que nos referíamos antes, nos interesa ponerla en relación con el hecho de que el verbo decir admite la doble selección modal (indicativo / subjuntivo) cuando aparece con una oración completiva, doble selección modal que, evidentemente, implica un cambio de significado: te digo que viene / te digo que venga, no me digas que viene / no me digas que venga. Tal contraste puede caracterizarse como la distinción entre "aserción" y "no aserción". Con indicativo, decir (en primera persona) parece comportarse, hasta cierto punto $^{7}$, como una especie de predi-

\footnotetext{
${ }^{5}$ En este trabajo nos apoyaremos en el sistema de unidades conversacionales del grupo Val.Es.Co: diálogo, intercambio y alternancia de turnos (en el nivel dialógico); intervención, acto, turno y subacto (en el nivel monológico). Véase Briz (2000) y Briz y Grupo Val.Es.Co. (2003). La mayoría de ellas las iremos introduciendo a lo largo de la exposición.

${ }^{6}$ Para un análisis de cómo estos conceptos se relacionan con la presencia de los modos indicativo y subjuntivo en las oraciones sustantivas, puede consultarse Grande Alija (2002: 249-270). También puede encontrarse en este trabajo un repaso de las propuestas más importantes que se han hecho al respecto.

${ }^{7}$ Sólo hasta cierto punto, porque decir no es un verbo asertivo, sino de enunciación. Sin embargo, resulta difícil referirse a un acto de enunciación sin implicar algún tipo de evaluación epistémica de la verdad de lo que se dice.
} 
cado asertivo que implica el compromiso del hablante con la verdad de lo representado en la oración sustantiva. En cambio, con subjuntivo, funciona más bien como un predicado realizativo de naturaleza directiva con el que el hablante pretende influir sobre el comportamiento futuro del oyente.

Pues bien, los diferentes usos que se van a considerar aquí de no me digas parecen tener su origen en aquellos en que decir actúa como un predicado con cierto potencial asertivo y que, en caso de recibir una realización plena, introduciría una estructura completiva en indicativo. Ninguno de estos valores parece surgir de la otra vertiente en que decir sirve para introducir una "no aserción" en la completiva mediante el subjunti$\mathrm{vo}^{8}$.

Hay un uso (el que se va a analizar en 4.1.4., mediante el cual el hablante expresa su ignorancia o falta de interés) que merece un comentario aparte. Tal valor se relaciona con una estructura en la que decir introduce una "interrogativa indirecta" de naturaleza disyuntiva: no me digas si viene o no viene, que no tengo ni idea9. Aunque en la "interrogativa indirecta" aparece el modo indicativo, su potencial asertivo queda en suspenso gracias a la presencia del transpositor $s i$.

\section{No me digas y las unidades fraseológicas}

Antes de proceder a la descripción y análisis de los usos discursivos de no me digas, habría que plantear brevemente, y a modo de orientación, algunos conceptos que ayudarán a entender mejor el comportamiento y evolución de esta expresión. Nos referimos al hecho de que no me digas muestra una clara tendencia a incorporarse a ciertas rutinas discursivas en las que ya no puede verse como resultado de la combinatoria libre, aunque determinada por las reglas del sistema, de las palabras que la forman, sino más bien como una combinación estable y preconfigurada que el hablante no puede alterar a discreción. Se entra así en el terreno de la fraseología y de las unidades fraseológicas $^{10}$.

\footnotetext{
${ }^{8}$ Tal vez la única excepción la constituyen ciertos usos de no me digas eso. Al tener el pronombre neutro una referencia textual, puede apuntar a cualquier tipo de discurso, incluidos los que no aportan un contenido asertivo (A: Cállate, B: No me digas eso. No ves que lo digo por tu bien).

${ }^{9}$ De hecho, en algunos usos en los que aparece este valor no me digas vendría a significar "no me preguntes". No en vano, frecuentemente este tipo de uso viene asociado a una interrogación previa del interlocutor.

${ }^{10}$ Como definición de referencia de lo que son las unidades fraseológicas, nos puede servir esta de G. Corpas (1996: 20): "Son unidades léxicas formadas por más de dos palabras gráficas en su límite inferior, cuyo límite superior se sitúa en el nivel de la oración compuesta. Dichas unidades se caracterizan
} 
De entre los diversos tipos de unidades fraseológicas que suelen tenerse en cuenta ${ }^{11}$, nos interesan aquí, en el plano de las clases de palabras con una función dentro de la oración, las locuciones y, en concreto, las locuciones verbales, y en el de los enunciados con función comunicativa, las fórmulas rutinarias. Como unidades fraseológicas que son, poseen algún tipo de fijación y pueden ser idiomáticas ${ }^{12}$. Aparte de estas propiedades, las fórmulas rutinarias, al ser enunciados con autonomía funcional, presentan alguna clase de independencia (Alvarado Ortega, 2010: 26). Las tres propiedades señaladas -fijación, idiomaticidad e independencia- pueden darse en diferentes grados y niveles.

El trabajo de Alvarado Ortega (2010), que se ciñe al campo de las fórmulas rutinarias, puede ser útil para aclarar estos conceptos.

Respecto a la fijación, recordemos que es el rasgo básico de cualquier unidad fraseológica, distingue tres tipos:

por su alta frecuencia de uso, y de coaparición de sus elementos integrantes, por su institucionalización, entendida en términos de fijación y especialización semántica; por su idiomaticidad y variación potenciales; así como por el grado en el cual se dan todos estos aspectos en los distintos tipos".

${ }^{11}$ Corpas (1996: 52) agrupa las unidades fraseológicas en tres esferas: colocaciones (fijadas en la norma y no constituyen enunciados), locuciones (fijadas en el sistema y tampoco son enunciados) y enunciados fraseológicos (están fijadas en el habla y sí tienen carácter de enunciados). Esta triple distinción es la que también recoge Ruiz Gurillo en diversos trabajos (por ejemplo, Ruiz Gurillo 2000: 172-176), aunque con otras definiciones. Según esta autora, los enunciados fraseológicos se caracterizan por su autonomía funcional, es decir, actúan como unidades comunicativas mínimas, como actos de habla. Se dividen en paremias (tienen autonomía textual y significado referencial) y fórmulas rutinarias (carecen de autonomía textual al venir dadas por una situación social concreta y poseen un significado social, expresivo o discursivo). Por su parte, las locuciones equivalen a clases de palabras (las hay, por tanto, nominales, verbales, adjetivales, adverbiales, etc.). Por último, las colocaciones, tampoco poseen autonomía funcional y se diferencian de las locuciones en el hecho de que no son idiomáticas y expresan, mediante moldes de creación propios de la sintaxis libre, de manera compleja realidades o conceptos que carecen de un término léxico específico en la lengua (máquina de afeitar, cepillo de dientes, hacer la cama...). Alvarado Ortega (2010) prefiere dejar las colocaciones fuera de las unidades fraseológicas. Las considera sintagmas usuales de la lengua pero carecen de fijación formal.

${ }^{12}$ Según Ruiz Gurillo (2000: 171), fijación e idiomaticidad son propiedades de las unidades fraseológicas. Sin embargo, mientras que la fijación es una propiedad necesaria, la idiomaticidad es tan sólo subsidiaria porque puede estar o no presente (las colocaciones, por ejemplo, carecen de ella). La misma autora define la fijación como "complejidad o estabilidad de forma y, adicionalmente, como defectividad combinatoria y sintáctica" (1998: 12). Que un sintagma esté fijado supone que "siempre se reproduce del mismo modo y que no admite grandes variaciones en su estructura" (Ruiz Gurillo, 2001: 19). Por último, la idiomaticidad consiste en que "el significado de la estructura no puede deducirse del significado de sus partes, tomadas por separado o en conjunto" (1998: 12). Para profundizar en estos conceptos, puede consultarse Ruiz Gurillo (1997), especialmente los capítulos IV y V. 
- fijación formal, que entiende como "estabilidad en el orden de sus componentes, en sus categorías gramaticales, en su inventario y en su transformatividad" (Alvarado Ortega, 2010: 27). Las fórmulas rutinarias actúan como un todo uniforme que puede tener variantes, aunque sin cambio de significado;

- fijación psico-lingüística: apunta al grado de convencionalización alcanzado, se refiere a la "estabilidad en su reproducción y en la frecuencia de uso que presentan las UFs [unidades fraseológicas] en general y las fórmulas rutinarias en particular. Los hablantes las recuerdan y las producen en bloque como una unidad léxica" (2010: 28);

- fijación semántico-pragmática: la tienen "cuando presentan un significado fijado por el uso que se les da en el contexto habitual en el que se producen" (2010: 29). Este tipo de fijación conduce a la idiomaticidad.

La idiomaticidad "consiste en la posibilidad de ausencia de contenido semántico en los elementos que componen la fórmula rutinaria" (Alvarado Ortega, 2010: 30). En otras palabras, el significado global de la fórmula no equivale al de la suma de los significados de sus componentes, sino que viene determinado por el que se ha fijado contextualmente.

Por último, la independencia ${ }^{13}$ se puede manifestar en diferentes niveles (Alvarado Ortega, 2010: 30-34):

- independencia entonativa: forman un grupo de entonación independiente. Tiene que ver con la posibilidad de expresar cierta fuerza ilocutiva propia;

- independencia distribucional: las fórmulas rutinarias pueden aparecer en el discurso tantas veces como sea necesario, debido a que su aparición viene determinada por el contexto situacional y la actitud del hablante;

- independencia textual: está ligada a la anterior e implica que la aparición de la fórmula rutinaria no viene provocada por el contexto lingüístico;

- independencia semántica: se relaciona con la fijación semántico-pragmática. Es decir, la fórmula rutinaria presenta un valor fijado por el contexto habitual, de modo que significa por sí misma, sin necesidad de otros elementos.

\footnotetext{
${ }^{13}$ Pensamos que el acudir a la noción de independencia para caracterizar las fórmulas rutinarias presenta alguna dificultad. En primer lugar, algunas de las definiciones de los tipos de independencia que se ofrecen resultan redundantes (de algún modo, hacen referencia a características ya implicadas por las propiedades básicas de la fijación y la idiomaticidad, tal es el caso de la independencia distribucional, textual y semántica). En segundo lugar, los diferentes tipos de independencia no se pueden situar en el mismo plano que las propiedades de fijación e idiomaticidad: con aquellos no se está apuntando a ciertos rasgos que tengan que ver con el hecho de ser un tipo de unidad fraseológica, sino simplemente con el de ser enunciados con una función comunicativa autónoma.
} 
- independencia sintáctica: tiene que ver con la aislabilidad de la fórmula en la estructura sintáctica. Se pueden extraer de la oración sin que implique un cambio en su estructura.

Lo importante de esto es que el ser una unidad fraseológica y, en concreto, una fórmula rutinaria no puede verse como una propiedad discreta, sino como un haz de rasgos que se manifiestan en grados variables. Esto mismo determina que se tengan realizaciones prototípicas (las que presentan todos los rasgos) y realizaciones menos prototípicas (las que sólo cuentan con algunos de ellos).

\section{Usos y funciones discursivas de no me digas $^{14}$}

\subsection{La orientación retrospectiva}

En este tipo de orientación el hablante torna su mirada hacia el discurso previo. Dicho de otra forma, el hablante reacciona, de diversas maneras, ante lo que el oyente acaba de decir en el turno anterior. Estas realizaciones son, por tanto, propias de las intervenciones reactivas (es decir, provocadas por lo que se ha dicho) y de la unidad conversacional del intercambio ${ }^{15}$.

\footnotetext{
${ }^{14}$ Para llevar a cabo nuestro análisis, nos hemos apoyado principalmente en ejemplos tomados del Corpus de Referencia del Español Actual (CREA) de la Real Academia Española (http://www.rae.es). Hemos completado la muestra con ejemplos tomados de internet, gracias a las herramientas que ofrece un buscador como Google, y con otros sacados del corpus de conversación coloquial del grupo Val.Es.Co. (Briz, 1995) y de diversas obras literarias que se citan al final. Por último, se han incorporado también algunos ejemplos de creación propia (aquellos que no tienen ninguna indicación sobre su procedencia). Como se puede apreciar, el corpus de ejemplos manejados, aunque predominan los de carácter coloquial o que imitan las características del registro coloquial, es bastante heterogéneo. Para nuestros objetivos, ello no es ningún inconveniente puesto que no intentamos analizar el comportamiento de no me digas en una variedad concreta del español como pueda ser la coloquial, sino identificar una buena muestra de los valores discursivos que esa forma apelativa presenta en diferentes variedades del español. A este respecto, la utilización de ejemplos inventados está perfectamente justificada: sólo se acude a ellos para ofrecer representaciones prototípicas de cada uso y para facilitar la realización de transformaciones y cambios que nos permiten poner de relieve algunas de sus características más relevantes. Además, todos los valores comunicativos analizados han sido identificados mediante ejemplos reales. Por último, quisiéramos aclarar que el nuestro no es un estudio cuantitativo. No pretendemos establecer cuáles son los valores comunicativos más frecuentes y típicos de una determinada variedad. En nuestro estudio todos son igual de representativos y útiles, dado que se trata de explicar cómo a partir de un valor inicial básico (el de la modalidad apelativa de carácter negativo del verbo decir) se ha podido llegar a una amplia diversidad de valores comunicativos.

${ }^{15}$ En el sistema de unidades del grupo Val.Es.Co, la intervención se define como "Unidad monológica máxima estructural, asociada al cambio de emisor, que se caracteriza por ser o por provocar una reac-
} 
La necesaria referencia al discurso precedente ante el que se reacciona puede manifestarse de diversos modos:

- De una manera explícita, retomando y repitiendo lo que el interlocutor acaba de decir:

(1) -Aprobó la última asignatura que le quedaba.

-No me digas que ha aprobado. Pero si no abrió un libro en todo el curso.

- De una manera implícita: la propia mecánica conversacional hace posible que no haya que repetir lo que se ha dicho, puesto que tal información está ya presente en el contexto:

(2) -Van a proponer una subida del iva.

- No me digas! Lo que faltaba para que el negocio se vaya a pique.

- Extrayendo las implicaciones y consecuencias que se derivan de lo que el hablante ha afirmado en el turno anterior. Entramos en el dominio de las inferencias pragmáticas:

(3) -Me voy a matricular en un máster en Biolingüística aplicada.

-No me digas que ya sabes lo que quieres.

- Mediante un demostrativo anafórico neutro con referencia discursiva o un sintagma nominal que designe el discurso previo:

(4) -Sólo me llamas cuando no tienes con quién salir.

-No me digas eso. Siempre que puedo quedo contigo.

ción lingüística” (Briz y Grupo Val.Es.Co., 2003: 17). Las intervenciones se dividen en iniciativas (provocan habla posterior, es decir, reacción por parte del interlocutor) y reactivas (vienen provocadas por una intervención iniciativa). Estas últimas se corresponderían con respuestas, conformidades, valoraciones, excusas o concesiones de lo anterior. En el mismo nivel monológico se encuentra la unidad del turno. Esta pertenece al plano social e implica por parte del interlocutor un reconocimiento y una aceptación. Se define de la siguiente manera: "Unidad social, responsable de la progresión conversacional, caracterizada por ser un lugar de habla rellenado con emisiones informativas aceptadas por los interlocutores mediante su atención manifiesta y simultánea (Briz y Grupo Val.Es.Co, 2003: 20). De acuerdo con esta caracterización, todo turno es, al mismo tiempo, intervención, pero no toda intervención acaba constituyéndose en turno. Para que esto ocurra necesita ser tenida en cuenta en el desarrollo del diálogo.

En el nivel dialógico, encontramos la unidad estructural del intercambio: "Dos intervenciones sucesivas de distintos emisores, una de inicio y otra de reacción" (Briz y Grupo Val.Es.Co, 2003: 28). El par adyacente de pregunta-respuesta sería un ejemplo prototípico de intercambio. En el plano social se tiene la unidad dialógica de la alternancia de turnos. La alternancia de turnos es al intercambio lo que el turno era a la intervención. Por tanto, toda alternancia de turnos implica un intercambio, pero no todo intercambio implica una alternancia de turnos. 
(5) - Cada día estoy más convencida de que no soy nada para ti. -No me digas esas cosas, que sabes que no son verdad.

4.1.1. Formas que incorporan un referente anafórico ("no me digas eso", "no me digas esas cosas"...)

De todos estos usos, los menos fijados son los que se recogen en los diálogos de 4 y 5. Otros ejemplos de este mismo tipo son los siguientes:

(6) A:

[LO SIENTO] ¿QUÉ QUIERES QUE HAGA?

B: NA(D)A/ QUE ME DIGAS CLARO LO QUE QUIERES/ ESO QUIERO QUE HAGAS/ QUE ME DIGAS SI QUIERES SEGUIR O SI QUIERES CORTAR/ PERO YO ASÍ NO PUEDO ESTAR/ NO PUEDO ESTAR TODO EL RATO YENDO Y PENSANDO QUÉ TE PASA $\uparrow /$ Y QUÉ ES LO QUE ESTÁS PENSANDO SI ES POR MÎ $\uparrow /$ ECHÁNDOME YO LA CULPA $\uparrow /$ O ES QUEQUÉ TE PASA EN TU CASA O QUÉ TE PASA CON

TUS AMIGOS\$

A: $\quad \$$ mira $\downarrow$ Blanca no- no $\$$

B: $\quad \$[$ PORQUE LA VERDAD ES QUE EN TU VIDA YA SABES

QUIÉN TE QUIERE DE VERDAD]

A: [iNO ME DIGAS ESO! TÚ SABES] QUE YO TE NECESITO// O SEA/ ES QUE NO (Briz, 1995: 85).

(7) -LOLI: Pepe no me ha dejado porque yo no me arreglara. Te juro que siempre he procurado agradarle, lo que pasa es que a una nunca le ha sobrado el dinero para ir a la última. Y, claro, se cruzó otra que sí iba.

-MAITE: Otra que tenía más sexi que tú y más idea.

-LOLI: No me digas eso, Maite. Menudo putón está hecha (A. Martínez Ballesteros, Pisito clandestino, SGAE, Madrid, 1992, CREA).

En estos ejemplos, no me digas eso es un enunciado de modalidad apelativa y, por ello, autónomo desde un punto de vista comunicativo. No en vano, podría constituir por sí solo turno y funcionar como acto ${ }^{16}$. No obstante, lo normal es que aparezca en intervenciones más complejas en las que figura como componente central (es el que aporta la fuerza ilocutiva) al que se hallan subordinados otros componentes proposicio-

\footnotetext{
${ }^{16} \mathrm{El}$ acto se define como "unidad estructural monológica, jerárquicamente inferior a la intervención, de la que es constituyente inmediato, que posee las propiedades de aislabilidad e identificabilidad en un contexto dado" (Briz y Grupo Val.Es.Co., 2003: 31). Es aislable porque puede constituirse por sí mismo en intervención y es identificable al poseer límites reconocibles. El acto expresa una única fuerza ilocutiva y presenta un contorno melódico propio.
} 
nales que suelen funcionar como justificación o explicación del acto directivo que representa no me digas eso ${ }^{17}$.

\subsubsection{Su condición de fórmula rutinaria}

Cabría preguntarse si no me digas eso, en esta clase de ejemplos, actúa como lo que podría caracterizarse ya como una unidad fraseológica y, en concreto, debido a su función comunicativa, como enunciado fraseológico y, más específicamente, como fórmula rutinaria.

Se aprecia que en ellos el sentido apelativo original se encuentra plenamente vivo, dado que se utilizan para rechazar el enunciado planteado por el oyente en el turno anterior $^{18}$. De este modo, se puede considerar que el sentido del enunciado es el resultado de la suma de sus componentes. No hay, pues, idiomaticidad. De hecho, el significado léxico del verbo decir sigue totalmente activo y puede ser retomado en un turno posterior, cosa que en otros usos no es posible:

(8) Juan Carlos Querido: vos como El Zorro sos peor que Alain Delon. Rafael: No, boludo, no me digas eso...

Juan Carlos: ¿Y qué querés que te diga? [...] (J.J. Campanella y F. Castets, El hijo de la novia, RBA, Barcelona, 2002, pág. 124, CREA).

Sin embargo, como se destacó en $₫ 3$., mientras que la idiomaticidad es una propiedad subsidiaria, la fijación es una propiedad necesaria (Ruiz Gurillo, 2000: 171). Decir mantiene plenamente activa la combinatoria sintáctica de un verbo de naturaleza transitiva.

A pesar de todo, parece que se puede hablar de cierto grado de fijación y especialización. Está claro que la variante más frecuente, más normal, es la que incluye el pronombre anafórico neutro (no me digas eso, no digas eso). Ciertamente, son posibles otras variantes en los que la referencia anafórica al discurso anterior la cumple el sintagma esas cosas:

\footnotetext{
${ }^{17}$ Siguiendo con la propuesta de unidades conversacionales de Briz y Grupo Val.Es.Co. (2003: 49), no me digas sería el subacto sustantivo director (tiene contenido proposicional y fuerza ilocutiva propia), mientras que los otros componentes proposicionales que lo acompañan serían subactos sustantivos subordinados.

${ }^{18}$ Dentro de la unidad conversacional del intercambio (dos intervenciones sucesivas de distintos emisores), no me digas eso aparece siempre como intervención reactiva y como segunda parte no preferida (Levinson, 1989: 294), dado que discute, rechaza o polemiza con lo planteado en la intervención precedente. No se favorece, pues, la expresión de la cortesía verbal.
} 
(9) Chica: ¡Olé los chicos guapos!

Yo (me giro hacía ellas): No me digas esas cosas que me pongo colorao

Chica: Es que el que es guapo, es guapo

Yo: Pues gracias

Chica: las que tú tienes (Internet: http://www.mclarenx.com/2008/07/18/miprimer-dia-de-comercial/).

En cambio, es poco probable que aparecieran en esa función otras expresiones como no me digas esas palabras, ni tampoco, con ese sentido, una forma con el pronombre neutro realzado: eso, no me lo digas. Sin embargo, se pueden incluir otros sintagmas (en el ejemplo de internet se podría haber dicho no me digas esas cosas tan bonitas) o modificadores:

(10) Carmen. -(A Pepe) Podías tener un poco de tacto.

Pepe.- Encima no me digas eso, que bastante me contengo (R. Mendizábal, De cómo Antoñito López, natural de Játiva, subió a los cielos, Marsó-Velasco, Madrid, pág. 42, CREA).

No hay pues, en sentido estricto, fijación formal. Tampoco se puede hablar de fijación psico-lingüística completa porque, aunque hay estabilidad y frecuencia de uso, no se ha llegado a una lexicalización de la fórmula, ni se puede defender todavía la existencia de fijación semántico-pragmática en sentido pleno porque todavía sigue manteniendo vivo su valor comunicativo de carácter apelativo. Hay que reconocer que se está produciendo cierto deslizamiento hacia el ámbito de la modalidad evaluativa y expresiva: al tiempo que el hablante reacciona ante una enunciación anterior y la rechaza, hay una evaluación subjetiva implícita de la misma de carácter negativo que sólo se puede determinar contextualmente (el hablante puede sugerir por diversos caminos que es una afirmación inoportuna, exagerada, fuera de lugar, desproporcionada, injusta...). Sin embargo, no ha llegado a imponerse a la modalización apelativa de base y sólo se puede explicar como un efecto contextual de sentido.

Respecto a la independencia, si se analizan las definiciones que Alvarado Ortega propone para las cinco clases de independencia que distingue (2010: 30-34), tienen mucho que ver, como ya se destacó antes, con su condición de enunciados, es decir, de unidades mínimas con función comunicativa. No es de extrañar, pues, que no me digas eso presente la mayoría de los tipos de independencia señalados por la mencionada autora $^{19}$.

\footnotetext{
${ }^{19}$ Entonativa, por poseer una modalidad de enunciación y una cierta fuerza ilocutiva; distribucional, porque puede aparecer en el discurso cuantas veces se requiera; textual, porque su aparición no de-
} 
En definitiva, no me digas eso muestra algunos rasgos que la acercan al funcionamiento de las fórmulas rutinarias, pero está todavía lejos de haber completado los procesos que conducen a la aparición de estas últimas.

\subsubsection{Formas que expresan una reacción afectiva al discurso previo}

En los ejemplos 1 y 2 del apartado 4.1. encontramos otros usos de no me digas que comparten con el que se acaba de analizar la referencia al discurso previo: se reacciona ante él. Hay, sin embargo, importantes diferencias: aquí no se rechaza la enunciación precedente del oyente, sino que se reacciona afectivamente ante ella mostrando sorpresa, extrañeza, incredulidad o contrariedad. De nuevo, los matices concretos sólo se pueden precisar contextualmente. Por otra parte, a diferencia del uso anterior, la fórmula no me digas se encuentra ya altamente lexicalizada.

Otros ejemplos son los siguientes:

(11) -Pues yo creo que he averiguado cómo se llamaba.

-No me digas (Ruiz Zafón, 2008: 310).

(12) Cagüen el copón, Tejada, la de cosas que pasan sin que uno se entere. ¿Sabías que Galván estuvo liado con las tramas del juego ilegal, y que hace cuatro años fue expedientado por amenazar con la pipa a un inspector de Bilbao?

-No me digas. Me cago en la leche puta. ¡A ver, Mario, un sifón que pite! ¡Y otra de callos y un tinto aquí para Quintanilla! (J. Marsé, Rabos de lagartija, Lumen, Barcelona, 2000, pág 311, CREA).

(13) G: [no/ yo- yo también conozco] mucha gente que ha idoo

L: no me- no me digas que tú conoces a gente

G: CHICA/ no/ que han ido al colegio de monjas yy/ al principio sí/ pero después/ en cuanto te han dao un poquito dee libertad $\uparrow$

E: se escaquean $\$$

G: $\quad$ $\quad \$$ las monjas ni verlas $₫(B r i z, 1995: 101)$.

pende del contexto lingüístico, sino del situacional; sintáctica, dado que se puede extraer la fórmula de la estructura sintáctica sin que esta se vea afectada. Con respecto a la independencia semántica, se puede decir que sólo la presenta en parte debido a que no hay una fijación semántico-pragmática completa. 
4.1.2.1. Cambios semánticos: el paso de la modalidad apelativa a la expresiva

Como decíamos, no me digas funciona como una verdadera unidad léxica. El sentido apelativo está totalmente perdido. Se ha producido un desplazamiento modal que nos lleva de la modalidad apelativa a la modalidad expresiva, es decir, de lo que es una modalidad de enunciación a una modalidad de enunciado. No me digas ha pasado a convertirse en un auténtico marcador de modalidad expresiva. En este proceso, se ha verificado una clara desmotivación semántica: el sentido global de la fórmula ya no es resultante de la suma de los significados de sus componentes. Hay idiomaticidad. Aparte del cambio en el valor modal, tampoco se mantienen operativos ni la negación ni el significado léxico del verbo decir:

(14) -María y Pedro han anunciado que se van a divorciar.

-iNo me digas!

-\# ¿Por qué no iba a decírtelo si es verdad?

En este otro ejemplo se aprecia cómo se produce el choque entre la lectura "literal" que propone un personaje y la idiomática (y expresiva) que prevalece para el otro:

(15) Licenciado F: Todo está... ¿gris? Polvoso. Cubierto por una capa de polvo. Esa montañita de arena... [...]

Empleado 1: Parece que no hicieron la limpieza, licenciado. Ahora me ocupo. Narváez, comuníqueme con el departamento de limpieza [...].

-Él: Es que llovió polvo, licenciado.

-Licenciado F: No me diga.

-Él: De la grieta.

-Licenciado F: No me diga, se lo estoy pidiendo: no me diga. ¿O alguien le ha dicho que su deber es informarme de este asunto? (Berman, 2004: 155-156).

4.1.2.2. Su comportamiento como unidad fraseológica (fórmula rutinaria / locución verbal)

Se observa que este no me digas expresivo aparece siempre en el marco de la unidad del intercambio $\mathrm{y}$, en concreto, en la intervención reactiva. Pero se aprecian ciertas diferencias. Si se toma como referencia la serie inicial de $\$$ 4.1.2. (ejemplos 11-13), en todos estos casos no me digas se comporta como unidad fraseológica. Sin embargo, sólo en los dos primeros (ejemplos 11 y 12), no me digas, al actuar como enunciado de modalidad expresiva, es un enunciado fraseológico y, en concreto, una fórmula rutinaria de modalidad expresiva que cumple los requisitos de fijación, idiomaticidad e independen- 
cia. En cambio, en 13 no me digas es una especie de predicado que introduce una estructura oracional, de modo que debería caracterizarse como locución verbal ${ }^{20}$.

Antes nos hemos referido a la idiomaticidad de esta expresión. Respecto a la fijación formal ${ }^{21}$, no me digas sólo admite variaciones relacionadas con el tratamiento (tú / usted). No tolera la sustitución por otra forma verbal ( ${ }^{*}$ no me dices) ni la inclusión de otro elemento, por ejemplo, el de un referente pronominal con el que se retome el discurso previo, ni la de un complemento circunstancial:

(16) -María y Pedro han anunciado que se van a divorciar. $-\#$;No me lo digas!/ \#; No me digas eso!/ ${ }^{*}$ Ahora no me digas

Aunque el nivel de inserción en la estructura sintagmática del discurso sea distinto en el caso de la fórmula rutinaria y en el de la locución verbal, está claro que en lo que se refiere a la mecánica modal y conversacional ambas son idénticas. De hecho, podría pensarse que el uso de no me digas como fórmula rutinaria, en el que ya se comporta como un genuino marcador conversacional, tiene su origen en la locución verbal expresiva que introduce una oración. La inmediatez del contexto hace innecesario repetir una información que ya esté presente en la intervención anterior. Por tanto, la fórmula rutinaria nace como resultado de un imperativo de eficiencia pragmática (¿para qué repetir lo que ya es conocido?).

\subsubsection{Algunos aspectos de su comportamiento pragmático y comunicativo}

\subsection{Referencia a una información ya conocida}

Teniendo en cuenta la mecánica conversacional a la que responde el uso de la fórmula rutinaria y la locución verbal (presencia en una intervención reactiva y expresión de la afectividad del hablante), ambas señalan a lo que, desde un punto de vista informativo, podría calificarse como información conocida, es decir, ya presente de algún modo en el contexto. La locución verbal no me digas lo hace de un modo explícito al incorporar dicha información al contenido de la oración que le sigue; en cambio, la fórmula rutinaria, al apoyarse en la intervención anterior, sólo lo hace implícitamente.

De acuerdo con lo dicho, este no me digas fijado y desemantizado se acerca al comportamiento semántico y discursivo de los predicados evaluativos de naturaleza factiva.

\footnotetext{
${ }^{20}$ En esta unidad fraseológica el complemento representado por me ya se encuentra fosilizado, no así la oración que le sigue.

${ }^{21}$ Evidentemente, también posee fijación psico-lingüística, es una fórmula convencionalizada, y fijación semántico-pragmática (no en vano, posee idiomaticidad).
} 
Desde un punto de vista informativo, aparece aquí la estructura típica de predicados factivos emotivos ${ }^{22}$ como lamentar, sorprenderse, alegrarse, etc., que expresan una reacción afectiva ante la información presupuesta comunicada por la oración sustantivada: el hablante torna la mirada hacia una información que al estar presente en el contexto (en este caso el contexto verbal representado por la intervención previa del oyente) puede considerarse, al menos desde un punto de vista pragmático, información presupuesta, es decir, ya conocida, ya planteada en el discurso. Desde el punto de vista de la modalidad subjetiva, su comportamiento es también similar: se reacciona ante ella para valorarla afectivamente ${ }^{23}$.

\subsection{Compromiso epistémico del hablante}

Hasta aquí se han destacado en el funcionamiento pragmático de esta unidad fraseológica las siguientes características: 1) a una intervención iniciativa le sucede otra reactiva; 2) la información que en la primera se presenta como nueva, en la segunda, al retomarla, se muestra como ya conocida y 3) el hablante manifiesta cierta reacción afectiva ante ella. Sin embargo, no hay que olvidarse de otro aspecto importante: el juego de atribuciones y compromisos epistémicos ${ }^{24}$ que se da en esta sucesión de intervenciones, puesto que dicha reacción afectiva se produce ante una información aportada por el oyente en la intervención precedente.

En la intervención de inicio, el responsable de ella presenta a su interlocutor una información que considera verdadera o razonablemente verdadera, a la par que relevante. A continuación, en la intervención reactiva el hablante apunta a esa información bien de un modo implícito, es decir, contextualmente, bien de un modo explícito, esto es,

\footnotetext{
${ }^{22}$ Para un acercamiento a las propiedades básicas de los predicados factivos, puede consultarse Grande Alija (1997: 374-382).

${ }^{23}$ Evidentemente, los predicados factivos emotivos, aparte de las ya señaladas de referencia a una información presupuesta y de reacción afectiva ante ella, presentan otras características de las que carecen estos usos de no me digas, como son el comportamiento con la negación (se mantiene la presuposición semántica aun cuando se niegue el predicado regente) y la presencia del modo de la noaserción, es decir, el subjuntivo en la oración sustantiva que introducen, y ello a pesar de que se estén refiriendo a algo que se considera verdadero (Lamento que te hayan despedido. Ya verás como encuentras pronto trabajo).

${ }^{24}$ En una interpretación amplia, la modalidad epistémica tiene que ver con la expresión del mayor o menor grado de compromiso del hablante con la verdad de lo que dice. Se manifiesta por medio de una gran variedad de recursos formales de naturaleza léxica y gramatical (verbos modales, partículas, modos, etc.).
} 
retomándola en su propia intervención, y la evalúa afectivamente mostrando que la ve como algo sorprendente o inesperado. Ahora bien, ¿qué posición epistémica asume el hablante con respecto a esa información? Se abre aquí toda una panoplia de posibilidades que en buena medida son responsables de que surjan matices expresivos que van de la simple sorpresa a la incredulidad más extrema. Nos encontramos ante hechos de naturaleza pragmática.

El hablante puede confirmar y aceptar plenamente el punto de vista expresado por su oyente en la intervención anterior; o bien al menos no lo cuestiona porque, aunque le resulte difícil creerlo, quizá no dispone de evidencias en sentido contrario y, en consecuencia, tiene que fiarse de lo que le ha dicho; o muestra sus dudas o reticencias; o, finalmente, expresa de modo claro su desacuerdo y rechazo. En todo esto resulta esencial el grado de crédito que el hablante otorga al oyente, su confianza en él, su conocimiento del tema, etc. Lo fundamental es no perder de vista cómo se refuerzan mutuamente o contrastan los puntos de vista de los responsables del intercambio conversacional.

Veamos a continuación algunos ejemplos de cómo el compromiso epistémico del hablante ante lo planteado por su oyente es variable:

(17) -Conque enterrando un perro -corta impaciente el gordo-. Qué extraño. El inspector Galván enterrando perros. ¿Por qué lo haría?

-Porque el perro estaba muerto, señor. Él lo había matado.

-No me digas. ¿Has oído eso, Tejada? ¿Y por qué lo mató?

-Porque era muy viejo y estaba enfermo, y pensaría que no valía la pena perder el tiempo llevándolo al matadero del veterinario... (J. Marsé, Rabos de lagartija, Lumen, Barcelona, 2000, CREA).

(18) -Tengo lotería de Ponferrada.

- ¿De Ponferrada? ¡No me digas! Pásame dos.

-Te paso uno por ser tú, pero no se lo digas a Rebolledo (VV.AA., El club de la Comedia Presenta Ventajas de ser incompetente y otros monólogos de humor, Aguilar, Madrid, 2001, pág. 211, CREA).

En estos dos ejemplos el hablante, como se aprecia en la continuación del diálogo, acepta como verdadera la información que su oyente le acaba de comunicar. En 17, al incorporarla como parte de la información presupuesta de la interrogación parcial de la tercera intervención; en 18, al ser requisito necesario para el cumplimiento del acto directivo que sigue a la fórmula rutinaria.

En cambio, en 19 el hablante más bien muestra su incredulidad ante lo que le ha dicho su oyente:

(19) -Creo que el médico acertó con su diagnóstico después de todo. 
-No me digas, Ramón. ¿De verdad lo piensas?

-Sí, me temo que sí (L. Beccaria, La luna de Jorge, Destino, Barcelona, 2001, pág. 415, CREA).

Por último, es frecuente un uso coloquial de no me digas en el que asume una interpretación irónica con la se muestra una falsa sorpresa y un rechazo claro de lo que el primer locutor acaba de plantear. Sólo contextualmente, y por la entonación irónica característica, se puede deducir la antífrasis:

(20) (Hablan del contrato de un futbolista con la SER)

-¿Qué gana la SER si le paga esos dos millones?

-El chico os puede compensar de otra manera.

-No me digas. ¿Nos dedicará un gol? ¿Un autógrafo?...

-Así no conseguiremos nada, Joserra. Si te pones en plan de cachondeo, no adelantamos nada (J.R. de la Morena, Los silencios de El Larguero, El País-Aguilar, Madrid, 1996, págs. 200-201, CREA).

\subsubsection{Formas que expresan una reacción afectiva y extraen una inferencia pragmática}

Junto a los ejemplos considerados hasta ahora existen otros que mantienen los siguientes rasgos fundamentales: 1) aparición, dentro de la unidad conversacional del intercambio, en una intervención reactiva; 2) reacción afectiva del hablante provocada por lo que su oyente acaba de decir (se sigue expresando sorpresa, extrañeza...) y 3 ) continúa habiendo idiomaticidad y fijación (no en vano, se trata de una locución verbal).

Sin embargo, hay una diferencia importante: la reacción afectiva que manifiesta el hablante no se dirige exactamente hacia lo que ha dicho su oyente en la intervención anterior, sino hacia lo que él mismo ha deducido a partir de la información que el oyente le ha aportado a lo largo de las intervenciones precedentes. Nos encontramos, pues, ante un proceso deductivo pragmático en toda regla efectuado por el hablante de la intervención reactiva. La sorpresa que este expresa se orienta hacia el resultado del proceso deductivo del que sólo él es el responsable. Tal inferencia necesariamente ha de hacerse explícita tras la fórmula expresiva. Por lo tanto, sólo puede aparecer la locución verbal no me digas que...

Antes de considerar otros aspectos de este uso, se recogen a continuación algunos ejemplos:

(21) -Había pensado en invitarle a comer. 
-Se le agradece, pero no puedo dejar el timón. Mi hijo se ha ido a Sarriá a tasar una colección y no están las cuentas como para ir cerrando cuando los clientes están en la calle.

-No me diga que tiene problemas de dinero (Ruiz Zafón, 2008: 323-324).

(22) -Sangüesa, soy Petra, te pedí hace tiempo un informe cerrado sobre las situaciones económicas de los guardias de seguridad de "El Paradís", en Sant Cugat. ¿Qué esperas para mandármelo, que llegue Navidad? ¿Piensas dármelo como una especie de regalo o algo así?

-Petra Delicado, ¿cuánto tiempo hace que no abres tu correo electrónico?

-No me digas que tu informe está ahí.

-Desde hace días.

- ¡Joder, Sangüesa, lo siento! Con todo este lío del papa ando despendolada (A. Jiménez Bartlett, Serpientes en el paraíso. El nuevo caso de Petra Delicado, Planeta, Barcelona, 2002, págs. 139-140, CREA).

(23) -Esto es muy grande -comentó Bárbara, atacando el mismo punto pero desde otro ángulo-. ¿No te sientes un poco solo?

-A veces es mejor estar solo que mal acompañado.

Bromeaba, pero podía haber dicho lo mismo en serio [...]

-No me digas que no tienes novia...

-Oye... tú haces muchas preguntas.

-Sí, pero todas fáciles.

-Pues no, no tengo novia, ni ligues, ni nada. Aparte de mis perros, no hay nadie que me quiera (A. Rojo, Matar para vivir, Plaza y Janés, Barcelona, págs. 131132, CREA).

(24) -También es lógico, Sofía. No todos los días y de un plumazo descubre una que su marido y su amante le ponen cuernos al unísono.

-Porque, ¿tú crees que Jorge está liado con aquella que lo esperaba a la puerta del Centro?

-No es que lo crea, es que por el beso en la boca que le dio al subirse al coche, lo deduje ipso facto. No me digas que no te diste cuenta.

-No me fijé, la verdad. Estaba tan obcecada contemplando a Ramón coger el taxi que me perdí ese detalle (L. Beccaria, La luna en Jorge, Destino, Barcelona, 2001, págs. 376-377, CREA). 


\subsubsection{Naturaleza de la inferencia pragmática}

\subsection{Carácter hipotético de la inferencia}

En primer lugar, como resultado de la mecánica conversacional en la que se inserta, tal inferencia es una verdad condicionada, es decir, dependiente de la verdad de otras proposiciones comunicadas previamente de forma implícita o explícita. Por esta razón, la fuerza de esa verdad no puede ser mayor que la de las proposiciones que la originan. En otras palabras, la deducción que el hablante realiza a partir de lo dicho por el oyente puede ser relevante, razonable, altamente probable, pero no deja de ser una hipótesis. De ahí también que el desarrollo natural de este tipo de intercambio sea que el oyente vuelva a intervenir para confirmar o descartar la hipótesis adelantada por el hablante. En los diálogos anteriores aparecen ejemplos de estos dos movimientos. A la luz de esto, se puede decir que este uso de no me digas que... no es propio, dentro del intercambio, de una intervención reactiva, sino más bien de una intervención de carácter mixto: reactiva (viene provocada por otra anterior)-iniciativa (provoca en el oyente una respuesta).

Hay otro indicio que pone de manifiesto el carácter hipotético de la deducción que se hace: nos referimos al hecho de que hay cierta fluctuación en cuanto a la modalidad de enunciación bajo la que aparece el enunciado con la locución verbal no me digas: aunque lo más frecuente y normal es que sea de carácter declarativo, no faltan ejemplos de modalidad interrogativa. En ellos, se manifiesta de forma más clara el carácter hipotético de la deducción planteada:

(25) - ¿A qué hora has quedado con el Fósil? -preguntó Porta.

-A las diez -contestó la periodista-, pero me han dicho que llegará un poco tarde.

-Creo que anda deprimido.

-¿Lo cesan por fin?

Bárbara Brisa preguntaba a ciegas, tratando de pescar cualquier cosa.

-Nada de eso, hija... Temas personales.

- ¿No me digas que tiene un lío de faldas?

-El Fósil no ha echado una cana al aire desde que los nacionales entraron en Madrid. Y eso ocurrió en 1939 [...] (A. Rojo, Matar para vivir, Plaza y Janés, Barcelona, 2002, págs. 22-23, CREA).

En relación con esto, cabe destacar que algunos de los ejemplos anteriores pueden someterse a una transformación que, una vez más, pone de relieve el carácter hipotético de la deducción. En efecto, aunque, en principio, el uso que se está analizando sólo aparece con la variante no me digas que..., en algunos de los ejemplos recogidos esta locu- 
ción verbal puede sustituirse por la fórmula rutinaria correspondiente no me digas seguida de un enunciado interrogativo. Este último plantea lo que al hablante le parece una hipótesis que se puede deducir razonablemente a partir de lo que su oyente ha dicho en la intervención precedente. Por ejemplo, este diálogo:

(26) -Pide lo que te apetezca.

-No me digas que te ha tocado la lotería.

-Algo así.

podría transformarse de la siguiente manera con un efecto expresivo similar:

(27) -Pide lo que te apetezca.

-¡No me digas! ¿Te ha tocado la lotería?

-Algo así.

\subsection{Fuentes informativas en que se apoya la inferencia}

Siguiendo con la naturaleza de la inferencia pragmática que realiza el hablante, se debe destacar que las fuentes informativas de las que se deriva son diversas. A veces se extrae directamente de la información factual descrita por el oyente:

(28) -Ayer mataron a doce.

-A diez.

- A mí me han dicho que a doce.

$[\ldots]$

-Yo los vi, y eran doce.

-La partida entera de El Chaqueta Negra.

-No me digas que han matado a El Chaqueta Negra.

-No, El Chaqueta Negra no estaba entre los muertos, él y otro se escaparon (D. Chacón, La voz dormida, Alfaguara, Madrid, 2002, pág. 84, CREA).

En este diálogo alguien manifiesta que han matado a la partida entera de El Chaqueta Negra. El interlocutor, a la vez que expresa su sorpresa, deduce de esa información algo que le parece razonable: que han matado a El Chaqueta Negra, deducción que, en el siguiente turno, se demuestra que no es correcta. Es el tipo de inferencia más cercana a los procesos deductivos del razonamiento lógico: de la verdad de lo más general se extrae la verdad de lo más particular.

Pero en otros casos, las inferencias que se producen se apoyan en procesos de carácter más bien pragmático. En concreto, se basan en las condiciones de adecuación pragmática que hacen que resulte razonable el plantear determinado acto de habla. Si se 
cumplen estas condiciones o requisitos previos, resulta entonces lícito deducir ciertas cosas y no otras. Esto se ve claramente en los ejemplos en los que en la intervención iniciativa que desencadena la reacción del hablante hay una interrogación:

(29) -La otra noche, cuando volvió de verte, mi padre la estaba esperando. Le partió los labios a bofetadas, pero no te preocupes, que se negó a dar tu nombre. No te la mereces.

-Tomás...

-Cállate. Al día siguiente, mis padres la llevaron al médico.

-¿Por qué? ¿Está Bea enferma?

-Enferma de ti, imbécil. Mi hermana está embarazada. No me digas que no lo sabías (C. Ruiz Zafón, La sombra del viento, Planeta, Barcelona, 2003, pág. 536, CREA).

Si el hablante que plantea la pregunta ¿Está Bea enferma? lo hace de modo sincero, entonces desconoce a ciencia cierta qué es lo que realmente le pasa a esa persona y, por lo tanto, resulta viable deducir que no sabe que está embarazada.

En este otro caso, la deducción que se realiza se aprovecha para cuestionar la oportunidad o relevancia comunicativa de la pregunta que se plantea:

(30) -¿Estás vivo o hablo con una aparición? -preguntó.

-No me diga que ha venido desde Villa Helios hasta aquí para soltarme eso.

-No. He venido porque hace meses que no sé nada de ti y me preocupas (Ruiz Zafón, 2008: 93).

Por último, existen ejemplos en los que la fuente informativa de la que el hablante infiere lo que dice se encuentra en la propia situación de discurso. Al ser esta, si no el único ingrediente, sí el principal, que interviene en el proceso deductivo, no hay una intervención previa que desencadene la reacción afectiva del hablante y, como consecuencia de ello, no me digas que...funciona al margen de la unidad conversacional del intercambio y se adscribe entonces a una unidad como la intervención:

(31) Más allá de las vías había una figura con los brazos en cruz, el viento la movía o ella misma se dejaba mecer, como si fuera un espantapájaros que pretendiera emprender el vuelo.

La figura alzó de pronto los brazos y dio una zapateta.

- ¿No me digas que también vino ese gracioso...? (L.M. Díez, El oscurecer (Un encuentro), Ollero y Ramos, Madrid, 2002, pág. 113, CREA).

A partir de la información visual que obtiene desde lejos el hablante, al tiempo que expresa su sorpresa, deduce que se trata de un personaje que ya conoce. 


\subsection{4. "No me digas" como fórmula rutinaria de naturaleza epistémica}

Dentro de la orientación retrospectiva, existe otro uso de no me digas que es también propio de la unidad conversacional del intercambio al aparecer en intervenciones reactivas. Con esa expresión el locutor pone de manifiesto su desconocimiento respecto al tema tratado en la intervención anterior. Son ejemplos como los siguientes sacados de internet:

(32) - Amenofix: Pues me habían dicho que la crema Nivea no valía para el volante o los asientos por que es exclusiva para pieles vivas. Pero si que hay otro tipo de crema que se le puede echar, lo que pasa que no recuerdo ahora el nombre.

-Vitor-in: Pues para el volante no lo se, pero para los asientos la Nivea va de lujo $\mathrm{y}$ te los deja muy bien.

-No me digas, no tengo ni idea, sólo lo que me comentaran, que había mucha gente que usaba Nivea para el cuero y que realmente no valía para nada, pero no tengo ni idea, no pude comprobarlo (http://rallyast.mforos.com/1227915/ 5827082- pregunta-volante/)

(33) [Cuenta su viaje a Covadonga] Tomamos un tentempié allí y bajamos camino del Santuario, solo voy a resaltar que muchísima gente devota a la Virgen hacía una enorme cola, (no se con que fín) pero yo bebí de una fuente que tenía 7 chorros y como todo el mundo bebía de ella y de los 7 chorros, pues yo también!! de ahí a que hoy en el trabajo me enterara de que se dice que todo aquel que bebe de sus 7 chorros se casa al año siguiente... (no me digas... no tengo ni idea)

También tiré una moneda en una especie de charca que había y eso sí!! pedí un deseito... a ver si se me cumple ( http://inaicool.wordpress.com/tag/viajes/ ).

En los dos casos se hace explícita la falta de conocimiento ("no tengo ni idea"). En 33, aunque no existe un diálogo real, sí lo hay implícito y sólo de este modo se puede explicar la aparición de este no me digas. Haría falta recuperar una intervención que podría ser algo así como “¿Y por qué dicen eso?".

En este uso, no me digas sólo puede aparecer como fórmula rutinaria, nunca como locución verbal, de modo que puede constituir por si sola acto en la intervención en la que aparece o, como ocurre en los ejemplos anteriores, como subacto adyacente modalizador. Desde una perspectiva semántica, no me digas es una fórmula rutinaria de modalidad epistémica: el hablante reconoce su falta de conocimiento, aunque no deja de incorporar un claro componente expresivo.

Este valor de no me digas cumple las propiedades típicas de las fórmulas rutinarias: fijación, idiomaticidad e independencia, si nos atenemos a la caracterización que de ellas da Alvarado Ortega (2010). Por ejemplo, la fijación formal es clara: la única variación posible es la debida a las formas de tratamiento. No se admite ninguna otra susti- 
tución o transformación. Tampoco es posible incluir ningún componente nuevo como, por ejemplo, un referente de implemento (\#no me digas eso, \#no me lo digas). Merece un comentario aparte la idiomaticidad. Como es sabido, puede surgir como resultado de la fijación semántico-pragmática de la fórmula: se acaba imponiendo el significado contextual típico, que termina por desbancar el significado original. En el uso que nos ocupa, es evidente que no me digas es ya una fórmula de modalidad epistémica. Sin embargo, este valor modalizador está claramente relacionado con el sentido apelativo original que, en cierto modo, todavía está presente (de alguna manera, el hablante, al no poder cooperar adecuadamente, le está pidiendo que no continúe con su enunciación) ${ }^{25}$. Conforme a esto, no me digas puede caracterizarse como fórmula semiidiomática ${ }^{26}$.

Respecto a su valor pragmático, habría que destacar que en este uso no me digas apunta de modo claro a las máximas del principio de cooperación de Grice (1975): el hablante no se niega a cooperar, puesto que responde y reacciona ante la intervención previa del oyente, pero muestra su incapacidad de cumplir las máximas de cantidad y la de calidad. En algún caso, se puede generar la implicatura de que el hablante, por los motivos que sean, no le interesa el tema planteado y que prefiere interrumpir la conversación al menos en lo que se refiere a ese asunto.

\subsection{La orientación prospectiva o función anticipatoria}

\subsection{1. "No me digas" con valor expresivo que anticipa una respuesta}

Dentro de la función anticipatoria encontramos un primer tipo de ejemplos como los siguientes:

(34) -Tu amiga me trae sin cuidado, Daniel, y algún día compartirás mi sentir. Lo que quiero es el libro. Prefiero obtenerlo por las buenas y que nadie salga perjudicado. ¿ Me explico?

A falta de mejores ideas me lancé a mentir como un bellaco.

-Lo tiene un tal Adrián Neri. Músico. A lo mejor le suena.

-No me suena de nada, y eso es lo peor que se puede decir de un músico.

\footnotetext{
${ }^{25}$ Téngase en cuenta que, como se apuntó en $\$ 2.3$., este uso de no me digas podría derivar de una estructura con una interrogativa indirecta disyuntiva: no me digas si vino o no vino, que no lo sé.

${ }^{26}$ Para Alvarado Ortega (2010: 40-42), la idiomaticidad se debe plantear como una propiedad gradual. De acuerdo con esto, existen fórmulas rutinarias idiomáticas, semiidiomáticas y no idiomáticas. Téngase presente que la idiomaticidad no es un requisito imprescindible para poder hablar de fórmula rutinaria.
} 
$[\ldots]$

-Hablaré con Neri, pero no creo que me lo devuelva, o que lo tenga todavía improvisé-. ¿Y usted para qué quiere el libro? No me diga que para leerlo.

-No. Me lo sé de memoria (Ruiz Zafón, 2003: 68-69).

(35) - ¿Y qué es lo que hace usted leyendo tanto sobre ángeles y demonios? No me diga que es un ex seminarista arrepentido (Ruiz Zafón, 2008: 282).

(36) - ¿Dónde tienes el coche? No me digas que ya lo has vendido.

En estos casos se sigue expresando sorpresa o extrañeza como en los usos analizados en los epígrafes 4.1.2. y 4.1.3. de la orientación retrospectiva. Por otra parte, este valor anticipatorio de la locución verbal comparte con ellos el mismo grado de fijación e idiomaticidad. Sin embargo, se diferencia de ellos en que este uso anticipatorio de la locución expresiva no aparece en el marco de la unidad conversacional del intercambio, sino en el de la intervención. Son, ciertamente, intervenciones peculiares en el sentido de que encierran dentro de sí lo que parece un diálogo ficticio, en concreto, un intercambio prototípico como el formado por una pregunta y su respuesta. No me digas que... adelanta la que podría ser una respuesta posible del interlocutor a la pregunta planteada. De hecho, en 34 aparece después una nueva intervención que rechaza la respuesta anticipada. Igual que en este caso se rechaza, se podría confirmar.

Que esta es la mecánica conversacional subyacente lo confirma el hecho de que los ejemplos anteriores se podrían reformular de tal manera que ese diálogo ficticio se hiciera explícito, como ocurre en esta nueva versión de 36:

(37) -¿Dónde tienes el coche?

-Ya lo he vendido.

-iNo me digas!

En definitiva, los últimos casos analizados son una muestra clara del paso progresivo que se produce desde la orientación retrospectiva, anclada en lo que el interlocutor acaba de decir, a la orientación prospectiva, en la que se anticipa un posible acto futuro de enunciación. De aquella, presenta la evaluación subjetiva típica de los ejemplos analizados en 4.1.2. y 4.1.3. De esta, la anticipación del acto de discurso que todavía no se ha realizado.

\subsubsection{Anticipación con actitud de rechazo}

La forma apelativa no me digas (y variantes) presenta otra serie de usos que tienen en común al menos dos rasgos básicos: en primer lugar, se anticipa el que podría ser el 
posible futuro discurso del oyente $y$, en segundo lugar, se hace con el propósito de rechazarlo.

Si se comparan estos usos con los valores expresivos del apartado 4.1.2., que implicaban una reacción de sorpresa ante lo dicho por el oyente, se observan diferencias. Estos últimos poseían un marcado carácter "presuposicional", dado que con ellos se reaccionaba ante algo ya planteado en la intervención previa. Además, frente a la actitud de rechazo de los valores que ahora nos interesan, aquellos siempre implicaban, si no una aceptación absoluta, al menos no un rechazo de la información ante la que se reaccionaba expresivamente, puesto que se trataba de algo presentado como real o en todo caso como no imposible (sólo en ciertos usos irónicos era evidente la actitud de rechazo).

Otra diferencia tiene que ver con el modo de integrarse en el discurso: en los usos expresivos era viable tanto la fórmula rutinaria independiente como la locución verbal que introduce una oración. En este nuevo uso sólo es posible la construcción verbal con oración completiva.

Por otra parte, los usos expresivos de no me digas / no me digas que... aparecían, por lo general, en la intervención reactiva de un intercambio. Por el contrario, tal tipo de restricción no afecta a los usos anticipatorios.

Finalmente, habría que destacar que frente al carácter idiomático y fijado de los usos expresivos, el valor anticipatorio de esta forma verbal todavía se ciñe estrictamente al significado propio de la modalidad apelativa: con no me digas que... el locutor pretende precisamente que su destinatario se abstenga de pronunciar el discurso que anticipa.

Este valor anticipatorio con actitud de rechazo se observa en ejemplos como los siguientes:

(38) -¿Por qué yo? -pregunté-. Y no me digas que porque soy tu autor favorito y todas las lisonjas con las que Sempere te ha aconsejado que me enjabones, porque si lo haces, ésta será la primera y última conversación que tengamos (Ruiz Zafón, 2008: 226).

(39) - ¿Puedo preguntarle por su interés en este asunto? Y no me diga que se le ha despertado la curiosidad sólo por vivir en la casa de la torre (Ruiz Zafón, 2008: 400).

(40) -Tienes que hacer algo, Juan -le dijo sin mirarle a los ojos, para no leer en ellos que nada de lo que le estaba contando tenía importancia-. Andrés no viene a clase, le dice a Maribel que sí, pero no viene, se pasa las mañanas sentado en un banco, en el polígono industrial, y no me digas que es normal porque no es normal. Te digo yo que no es normal (A. Grandes, Los aires difíciles, Tusquets, Barcelona, 2002, pág. 526, CREA). 
(41) La última pregunta y la más importante:

¿Alguien en su sano juicio puede creer que esta sociedad inmadura, estúpida y enferma no va a cambiar nunca?

Pues se equivocan. Cambiará por el amor o por el dolor, pero cambiará.

Y por favor, no me diga que el hombre siempre ha sido igual de vicioso, porque no es cierto. Bueno, sí es cierto, pero ahora es mucho más: más mezquino y más vicioso (B. Ameztoy, Escuela de mujeres, Oberon, Madrid, 2001, pág. 153, CREA).

Como consecuencia del carácter anticipatorio y la expresión de una actitud de rechazo hacia el punto de vista anticipado, el discurso adquiere una orientación netamente polémica.

Respecto al carácter anticipatorio, es cierto que el hablante adelanta el que podía ser un discurso futuro del oyente. Se anticipa, pues, lo que todavía es una mera potencialidad. Sin embargo, normalmente adelantamos lo que resulta previsible, lo que se ajusta a la forma habitual de pensar o hablar de una determinada persona. En este sentido, la anticipación se apoya mucho en lo ya conocido, lo cual supone, en cierto modo, que se diluya la diferencia entre la orientación retrospectiva y prospectiva ${ }^{27}$. Esto es especialmente claro en los casos en que aparece una variante en tercera persona del plural:

(42) S: allí mira// te paran en la carretera// la tarjetita/ te la meten en el ordenador// chiin// cuarenta y cuatro años/ cabrón// estoy de seis meses// chsss seis meses en chirona y como $((\ldots))$ ¡hostia macho!

A: pues a mí- a mí que no me digan dee- de/ como ejemplo’e democracia Estados Unidos

S: ¡calla $\downarrow$ por Dios $\downarrow$ calla! (Briz, 1995: 193).

(43) Primero, no había crisis. Ahora que, por fin, la hay, el Gobierno se parapeta en el argumento de que es una crisis de carácter mundial. Todo el mundo lo sabe. Repetirlo no sirve de nada. La gente espera alguna cosa más. Y no digan que es muy poco lo que se puede hacer: Obama está cambiando su país -y de rebote, el mundo- en plena crisis (Ramoneda, 2009: 12).

La formulación impersonal se utiliza para adelantar y rechazar un discurso que ya es un lugar común, un tópico (que Estados Unidos es un ejemplo de democracia, que no se puede hacer nada ante la crisis). El carácter impersonal con se presentan indica que son afirmaciones que no se atribuyen a nadie en concreto, que forman parte de lo que es la opinión aceptada de modo general, que pertenecen a una visión del mundo que "la

\footnotetext{
${ }^{27}$ Recordamos que utilizamos estas dos orientaciones simplemente como un modo de organizar nuestra exposición, no porque creamos que se trata de dos usos comunicativos sin puntos de encuentro.
} 
mayoría" da por buena. A este respecto, tienen algo de discurso repetido, ya conocido, nos remiten a lo ya dicho. Sin embargo, también hay que admitir que esos mismos ejemplos presentan cierta orientación polémica y anticipatoria, dado que sirven para preludiar y desacreditar cualquier discurso futuro que siga la línea marcada por el lugar común que se rechaza.

\subsubsection{Naturaleza polémica de la anticipación}

La naturaleza polémica del discurso así planteado se encuentra íntimamente ligada a su carácter polifónico. No en vano, se trata de contrastar diferentes puntos de vista: el defendido por el hablante o locutor responsable de la enunciación y el que se atribuye a otra persona. Los ejemplos considerados dejan claro cómo se reflejan tales puntos de vista: en todos los casos no me digas expresa la actitud de rechazo del hablante, la oración sustantiva recoge la opinión que se cuestiona. Frecuentemente, la posición del hablante queda implícita, pero puede expresarse de forma abierta en la continuación del discurso, tal como se puede apreciar en el ejemplo 40 ( $y$ no me digas que es normal porque no es normal. Te digo yo que no es normal) y en el 41 (no me diga que el hombre siempre ha sido igual de vicioso, porque no es cierto)

En definitiva, los ejemplos recogidos tienen algo de diálogo fosilizado en el que se anticipa una posible intervención del oyente. De hecho, en algunos de los textos (ejemplos 38 y 39) se observa que el hablante plantea una pregunta y a continuación, en el mismo turno, mediante la expresión apelativa que estudiamos, el propio hablante adelanta la que podría ser una respuesta posible del oyente a la pregunta inicial.

Para ser más exactos, los ejemplos anteriores tienen más bien algo de diálogo truncado en el que se ha eliminado la intervención que precisamente se anticipa. Se podría hacer un ejercicio de "reescritura" para recuperar la intervención "desaparecida". El ejemplo 40 podría transformarse de la siguiente manera:

(44) A: Tienes que hacer algo, Juan -le dijo sin mirarle a los ojos, para no leer en ellos que nada de lo que le estaba contando tenía importancia-. Andrés no viene a clase, le dice a Maribel que sí, pero no viene, se pasa las mañanas sentado en un banco, en el polígono industrial.

B: No te preocupes, a su edad es normal.

A: No me digas que es normal porque no es normal. Te digo yo que no es normal.

Como resultado de la reescritura propuesta, no me digas pierde su carácter anticipatorio y se limita a recoger y rechazar el punto de vista expresado en el turno anterior. 
Para terminar, quisiéramos poner de relieve que la aparición del conector copulativo delante de la forma apelativa negativa refuerza su carácter polémico y anticipatorio. Sin él, se pierde el sentido polémico y nos enfrentamos a usos como los descritos en el apartado 4.2.1. Compárese el ejemplo 39, que repetimos, y la nueva versión sin tal conector:

(39) - ¿Puedo preguntarle por su interés en este asunto? Y no me diga que se le ha despertado la curiosidad sólo por vivir en la casa de la torre (Ruiz Zafón, 2008: 400) (anticipación y rechazo).

(45) ¿Puedo preguntarle por su interés en este asunto? No me diga que se le ha despertado la curiosidad sólo por vivir en la casa de la torre (anticipación y sorpresa).

Antes de proseguir en el análisis de otros usos anticipatorios de no me digas, quisiéramos dejar claro que el resto de valores tiene su origen en este que hemos caracterizado como "anticipación con actitud de rechazo". Todos ellos, al igual que el último visto, presentan el rechazo de una proposición y el refuerzo de la contraria. Cambian los valores expresivos y los rasgos formales. En esta evolución va perdiendo peso el aspecto de anticipación y cobra mayor importancia el de refuerzo de una proposición.

\subsubsection{Anticipación con valor exclamativo}

Cuando no me digas que... introduce una oración negativa como en esta intervención:

(46) -Lo entiendo, Edmundo. Lo malo es que no acabo de creérmelo. No creo que sea por eso. Tú podrías encontrar otro trabajo si quisieras. El motivo es que te da igual quién gane. Pero tú no eras así. Y no me digas que no se han conseguido cosas a costa de muchas luchas, luchas que se perdieron (B. Gopegui, Lo real, Anagrama, Barcelona, 2001, pág. 271, CREA).

su funcionamiento discursivo parece ser el mismo: el hablante estaría anticipando una posible objeción del oyente a su propio punto de vista. Así, en el ejemplo anterior se rechaza "que no se han conseguido cosas a costa de muchas luchas" y, en consecuencia, se está defendiendo la postura contraria de que "se han conseguido cosas a costa de muchas luchas". Como ocurría en los ejemplos del apartado anterior, hay un refuerzo implícito de la proposición contraria.

En otros casos, ese refuerzo pragmático parece asumir una orientación más expresiva hasta el punto de que se podría hablar, en cierta medida, de una fórmula especializada en una función exclamativa. En concreto, esto ocurre cuando se hace referencia a una propiedad gradual o a una cantidad. El resultado es una especie de ponderación pragmática de naturaleza exclamativa. Por ejemplo, no me digas que no es guapo se in- 
terpretaría como iqué guapo es! ¿no? o no me digas que son pocos se entendería como ¡son muchos! ¿no?. Con todo, y así lo hemos intentado reflejar en las paráfrasis, se mantiene cierto valor interactivo típico de la modalidad apelativa, dado que se parece pedir la confirmación del oyente.

En esta clase de usos parece haber ya desaparecido el sentido polémico de antes: el hablante no trata de anticipar una posible objeción del interlocutor. Más bien pretende destacar lo inviable de no $p$ para realzar expresivamente la opción contraria, $p$. Hay que tener en cuenta que los enunciados de modalidad exclamativa, aparte de su componente expresivo, incorporan una inequívoca dimensión asertiva:

(47) P: [(RISAS) $/ /^{\circ}$ (oye)/ que hemos dicho de todo $)^{\circ} \$$

C:

$$
\text { [hemos dicho }=\text { ] }
$$

P: $\quad$ [la verdad]

$\mathrm{C}:=$ la verdad/ pero además bien/ con ganas// ¿¡no me digas que no habrá salido clarito!? (Briz, 1995: 224).

(48) -No quiero hablar sin conocimiento de causa sobre algo que afecta a personas que están sufriendo y cuya intimidad merece respeto. Quiero decir, además, que lamento mucho las especulaciones gratuitas vertidas por algún compañero en los últimos días. Creo que debemos centrarnos en lo que ahora nos preocupa, y dejar que de hechos como ése se encargue la justicia.

-Espero que lo haya oído el comandante -deseó Chamorro.

-No me digas que no es buena gente -añadió Marchena.

-Es listo -dije, con admiración-. Sabe que tiene poder, y que el poder no se puede usar al tuntún, metiéndose en cualquier charco (L. Silva, El alquimista impaciente, Ediciones Destino, Barcelona, 2000, pág. 76, CREA).

(49) -Eres un impresentable, Jorge. No te aguanto más. Esto es tan ridículo que ya ni me da risa, se me ha pasado de rosca y ahora lo único que quiero es despertarme de esta pesadilla, porque no me digas a mí que no es absurdo lo que nos está pasando.

-Y tan absurdo (L. Beccaria, La luna en Jorge, Destino, Barcelona, 2001, pág. 104, CREA).

\subsubsection{Refuerzo de la aserción}

\subsubsection{No me digas que no en inciso}

La construcción no me digas que no puede aparecer como inciso tras un enunciado de carácter afirmativo. Es lo que ocurre en estos ejemplos: 
(50) No sé por qué, se me ocurrió que había entre los jóvenes y el indigente de la careta una misteriosa conexión. Los dos tomaban notas en un bloc de espiral y me pareció que hacían comentarios críticos sobre la actuación del pedigüeño. Me acerqué disimuladamente a ellos en el momento en el que uno decía:

-Es que este Gutiérrez es un genio, no me digas que no. Ha conseguido más de dos mil pesetas en un rato (J.J. Millás, Articuentos, Fernando Valls, Alba Editorial, Barcelona, 2001, págs. 221-222, CREA).

(51) Me prueban un collar. Es negro con piedras brillantes de no se qué diseñador. Este me queda bien, aquél me queda pequeño, un poco caro... un mucho caro... y alguien que dice que este tipo de tiendas convierte a humanos normales en humanos gilipollas: je, je, risas. No lo llevo puesto, no lo compramos, pero sí mi comida antialergias de unos cuantos euros el kilo. Me parece exagerado el precio del collar; sí, lo es, dicen sobre mi chata cabeza. Casi te diría que una vergüenza; sí, casi lo es, vuelven a hablar en lo alto... Pero es que le queda tan bien, se ve tan bonita, es precioso, no me digas que no, no me digas que no... no, no te lo digo, es muy bonito, y nosotros no tenemos hijos y... podríamos comprárselo y... Ofelia se merece eso y más y... total te lo vas a gastar en cuatro tonterías y... (internet: http://www.canarias7.es/blogs/ofelia/2009/04/un-collar.html).

Esto supone que la proposición que se refuerza ya no se tiene que deducir pragmáticamente como en los ejemplos anteriores, sino que se expresa abiertamente y en primer lugar. El comentario incidental sigue manteniendo el carácter negativo de la proposición afectada. En el ejemplo 50, la proposición que se quiere afirmar ("Gutiérrez es un genio") la expresa directamente el primer enunciado y el comentario parentético pospuesto no hace más que reafirmarla. De hecho, se podría repetir parcialmente ("no me digas que no lo es"). Funciona ya como un marcador de refuerzo de una aserción. Que el grado de fijación es mayor que en el de otros casos lo pone de manifiesto este otro ejemplo:

(52) - Maldita sea. Yo lo hago por mi hermana, ¿sabe usted?, por mi hermana únicamente, que me da mucha lástima. Bien lo sabe Dios. Pero maldigo al Partido, y a El Chaqueta Negra, y a la madre que los parió. El maldito Partido es el que tiene la culpa de todo. Usted me perdonará si la ofendo, pero si el dichoso Partido sirviese para algo no estaríamos como estamos, señora Celia, no me diga usted que no, que tiene tela la cosa. Yo le llevo al médico esta noche, pero nunca más (D. Chacón, La voz dormida, Alfaguara, Madrid, 2002. págs. 96-97, CREA).

No me diga usted que no está afectando, y reforzando, una proposición negativa ("no estaríamos como estamos") y su interpretación es exactamente la contraria a la que tendría No me diga usted que no estaríamos como estamos (> "estaríamos como estamos"), que sería el resultado de convertir el enunciado parentético no me digas que no en un predicado que introduce una proposición negativa. En definitiva, la fórmula se ha 
convertido ya en un marcador de refuerzo asertivo tanto si la proposición afectada es afirmativa (ejemplos 50 y 51) como negativa (ejemplo 52).

\subsubsection{No me digas en construcción parentética}

Los últimos ejemplos considerados se pueden ver como la antesala de la evolución final de la fórmula no me digas, tal como aparece usada en este diálogo:

(53) -Si es que no hay manera, Daría, cuanto mejor le va al padre en los negocios y a más gente influyente trata, más desprecian ellos el dinero.

-Jolines, porque lo tienen.

-De lo de la abuela, poco les debe quedar.

-Claro, a base de malrotarlo desde el principio. Tampoco fue consideración, no me diga, vender por cuatro perras los muebles tan buenos de la difunta señora, que parecía que les quemaba tenerlos. Menos mal que muchos se los llevó Santi. Pero también en América, tan lejos... A usted aquello la trastornó bastante (C. Martín Gaite, Nubosidad variable, Anagrama, Barcelona, 1994, CREA).

O en este otro texto:

(54) Lo que son las cosas, ¿eh? Cualquiera diría que íbamos a tener este día tan precioso, que menudo día, no me diga usted, hombre, no me diga usted.

[...] ¿Cómo? ¿Qué usted no sabe cómo ha sido este lío? ¡Anda, Dios! Lo que me faltaba oír. ¡Si todo el mundo lo sabe! No me diga (A. Zamora Vicente, Narraciones de lo real y lo Fantástico. Barcelona, Editorial Bruguera, 1977, págs. 145155, tomado de http://www.biblio-zamoravicente.es/Biblioteca\%20virtual/caute la/cautela.htm).

Como se puede apreciar, no me digas es de forma inequívoca un marcador de refuerzo asertivo. Creemos que el origen de este valor se encuentra en los usos anticipatorios que se han descrito en los apartados anteriores. La fórmula se ha desprendido de cualquier recuerdo de la oración sustantiva que originariamente anticipaba una posible objeción del oyente y que, en consecuencia, expresaba el punto de vista contrario al que el hablante realmente defendía. Ahora la postura de este último se comunica de manera explícita y no me digas se limita a reforzarla a la manera de una especie de operador discursivo de naturaleza parentética.

El proceso de evolución y especialización de no me digas se puede representar con la siguiente serie de ejemplos:

(55) a. No me digas que esto no lo puede hacer cualquiera

b. Esto lo puede hacer cualquiera, no me digas que no

c. Esto, no me digas, lo puede hacer cualquiera 
No me digas se ha desemantizado y fijado, y como resultado de ello podría afectar tanto a una proposición afirmativa como a una negativa:

(56) a. Esto, no me digas, lo puede hacer cualquiera

b. Esto, no me digas, no lo puede hacer cualquiera

En esta clase de usos, no me digas ha alcanzado ya una alto nivel de idiomaticidad y presenta una clara fijación formal (sólo admite cambios en el morfema de persona derivados de las formas de tratamiento, pero no otras variaciones como la inclusión de otros sintagmas o la transformación de su estructura sintagmática). Además, en virtud de su carácter parentético, permite cierta movilidad en la estructura sintagmática del enunciado.

\subsection{Resumen}

En la siguiente tabla aparecen recogidas las principales características consideradas a lo largo de los apartados del epígrafe 4:

\begin{tabular}{|c|c|c|c|c|c|c|c|}
\hline & $\begin{array}{l}\text { orientación } \\
\text { retrospectiva }\end{array}$ & $\begin{array}{l}\text { orientación } \\
\text { prospectiva }\end{array}$ & $\begin{array}{l}\text { fijación } \\
\text { (formal) }\end{array}$ & $\begin{array}{l}\text { idioma- } \\
\text { ticidad }\end{array}$ & $\begin{array}{l}\text { indepen- } \\
\text { dencia }\end{array}$ & locución & $\begin{array}{l}\text { fórmula } \\
\text { rutinaria }\end{array}$ \\
\hline $\begin{array}{l}\text { No me digas eso (\$ } \\
\text { 4.1.1.) }\end{array}$ & sí & no & no (1) & no & sí & no & no \\
\hline $\begin{array}{l}\text { No me digas de } \\
\text { reacción afectiva } \\
(\$ 4.1 .2 .)\end{array}$ & sí & no & sí & sí & sí/no & sí & sí \\
\hline $\begin{array}{l}\text { No me digas de } \\
\text { reacción afectiva } \\
\text { con inferencia ( } \$ \\
\text { 4.1.3.) }\end{array}$ & sí & no & sí & sí & no & sí & no \\
\hline $\begin{array}{l}\text { No me digas de } \\
\text { modalidad episté- } \\
\text { mica ( } \$ 4.1 .4 .)\end{array}$ & sí & no & sí & $\begin{array}{l}\text { sí/no } \\
(2)\end{array}$ & sí & no & sí \\
\hline $\begin{array}{l}\text { No me digas de } \\
\text { anticipación de } \\
\text { respuesta ( } \$ 4.2 .1 .)\end{array}$ & no & sí & sí & sí & no & sí & no \\
\hline $\begin{array}{l}\text { No me digas de } \\
\text { anticipación y } \\
\text { rechazo }(\$ 4.2 .2 .)\end{array}$ & no & sí & no & no & no & no & no \\
\hline $\begin{array}{l}\text { No me digas } \\
\text { exclamativo ( } \$ \\
4.2 .3 \text {.) }\end{array}$ & no & sí & no & no & no & no & no \\
\hline $\begin{array}{l}\text { No me digas de } \\
\text { refuerzo asertivo } \\
\text { ( } \$ 4.2 .4 \text {.) }\end{array}$ & no & no (3) & sí & sí & no & no (4) & no (4) \\
\hline
\end{tabular}


Notas aclaratorias:

(1) No obstante, existen indicios de que se puede estar verificando cierta fijación formal (\$ 4.1.1.1.).

(2) La hemos caracterizado como fórmula semiidiomática.

(3) Aunque estos usos asertivos tienen su origen en la función de anticipación y rechazo, en ellos se diluye la diferencia entre la orientación retrospectiva y la prospectiva.

(4) Sólo aparece como inciso que comenta una aserción previa.

\section{Unidades fraseológicas, gramaticalización y el factor pragmático}

\subsection{Introducción}

El tratamiento conjunto que se ha llevado a cabo de las diversas realizaciones de no me digas ha venido motivado por el deseo de llamar la atención sobre el hecho de que la combinatoria sintagmática de un mismo componente léxico (verbo decir), una misma categoría modal (modalidad apelativa) y unos mismos morfemas (negación, $2^{a}$ persona del singular) conduce a distintas realizaciones pragmáticas en las que se observan importantes diferencias relacionadas con su aparición en la mecánica conversacional y discursiva, con los contenidos modales expresados, con el grado de fijación e idiomaticidad que manifiestan y con el nivel de inserción en la estructura sintagmática. Son también muestra de la presión que los usos discursivos ejercen sobre el propio sistema, al que obligan a redefinirse y a aceptar nuevos patrones de codificación.

Analizados en conjunto, los diversos usos considerados pueden verse como puntos destacados o hitos de una escala en la que se considere el cambio gradual que afecta a los siguientes aspectos:

- Grado en que se mantiene la modalidad apelativa y, en contrapartida, grado en que surgen nuevos valores modales.

- Grado en que es posible variar las propiedades formales (sintácticas y morfológicas) de la combinatoria sintagmática original.

- Grado en que el significado léxico del verbo decir sigue siendo transparente y, por último, grado en que el significado de la combinatoria sintagmática es resultado de la suma de los significados de sus componentes. 
$\mathrm{El}$ anterior recorrido escalar puede plantearse como un proceso creciente de gramaticalización en el que van adquiriendo un mayor peso dos propiedades de las unidades fraseológicas: la fijación formal y la idiomaticidad ${ }^{28}$.

En la parte izquierda de la escala estarían los usos de no me digas eso (\$4.1.1.) y los anticipatorios que expresan rechazo de no me digas que... (\$ 4.2.2.); en la parte central, los de no me digas que se han asignado a la modalidad epistémica ( $\$ 4.1 .4$.); y en la parte de la derecha, los expresivos de no me digas (que) (\$4.1.2. y 4.1.3.) y los asertivos de no me digas ( $\$$ 4.2.4.2.).
(+) modalidad apelativa
(-) modalidad apelativa
(-) fijación
(+) fijación
(-) idiomaticidad
$(+)$ idiomaticidad
(-) GRAMATICALIZACIÓN
(+) GRAMATICALIZACIÓN

\subsection{El proceso de gramaticalización}

La gramaticalización puede caracterizarse como un proceso de cambio lingüístico por el que ciertas unidades léxicas y construcciones lingüísticas acaban asumiendo una función gramatical ${ }^{29}$. Como consecuencia de este proceso, las unidades implicadas experimentan importantes cambios formales y de contenido.

Aunque a primera vista la gramaticalización, al ser una teoría sobre el cambio lingüístico, se sitúa en la perspectiva diacrónica, en realidad no deja de conectar e integrar sincronía y diacronía, puesto que intenta explicar algunos rasgos de la sincronía a partir de la diacronía y, alternativamente, ver reflejados rasgos de la diacronía en la sincronía de una lengua determinada (Sánchez Marco, 2008: 1826). De acuerdo con esto, aunque nuestro acercamiento es fundamentalmente un análisis sincrónico de cómo no me digas ha desarrollado valores formulísticos y de cómo los usos pragmáticos actuales se relacionan con los rasgos formales y semánticos originales de esa expresión, no cabe duda de que puede beneficiarse de esta aproximación teórica.

\footnotetext{
${ }^{28}$ Precisamente, Ruiz Gurillo (2010: 173) incide en las interrelaciones que se dan entre gramaticalización y fraseología. Considera que las herramientas teóricas de la primera proporcionan una explicación de las propiedades de fijación e idiomaticidad de la segunda.

${ }^{29}$ Hopper y Traugott (1993: XV) la definen como "the process whereby lexical items and constructions come in certain linguistic contexts to serve grammatical functions, and, once grammaticalized, continue to develop new grammatical functions".
} 
En este marco, hay dos aspectos de la gramaticalización que nos interesan especialmente: 1) el carácter gradual de los cambios formales y semánticos que se verifican en ese proceso y 2) las motivaciones pragmáticas que lo desencadenan.

\subsubsection{Carácter gradual de los cambios}

Con respecto a la primera cuestión, el cambio de categoría puede plantearse como una gradación en el que de una categoría léxica se llega a una forma más reducida y gramatical. Hopper y Traugott (1993: 7) proponen el siguiente paso gradual (cline) ${ }^{30}$ : content item $>$ grammatical word $>$ clitic $>$ inflectional affix

Por su parte, J. Bybe ${ }^{31}$ organiza el paso de la categoría léxica a la gramatical en tres estadios y considera los cambios que en cada uno de ellos se produce en el nivel morfológico, fonológico, léxico, distribucional, etc. La siguiente tabla (tomada de Cuenca y Hilferty, 1999: 157) refleja el continuum de la gramaticalización:

\begin{tabular}{|l|l|l|}
\hline \multicolumn{1}{|c|}{ LÉXICO } & \multicolumn{1}{c|}{ GRAMATICAL } \\
\hline i) lexema & $>$ auxiliar, partícula & $>$ afijo \\
\hline ii) polisilábico & $>$ monosilábico & $>$ segmento único \\
\hline iii) clase abierta & $>$ clase cerrada amplia & $>$ clase cerrada reducida \\
\hline iv) posición libre & $>$ relativamente fija & $>$ totalmente fija \\
\hline v) relativamente frecuente & $>$ bastante frecuente & $>$ obligatorio \\
\hline vi) rico semánticamente & $>$ más general & $>$ reducido o vacío \\
\hline
\end{tabular}

La gramaticalización culminaría en lo que se ha venido llamando "reanálisis", es decir, un cambio en las propiedades formales y semánticas del elemento léxico original, que conduciría a una "descategorización" o paso de una categoría mayor (léxica) a una categoría menor (funcional). En el plano semántico, se verificaría una generalización o desemantización (semantic bleaching) entendida como paso de un significado léxico a un significado gramatical.

\footnotetext{
${ }^{30}$ Que se podría aplicar perfectamente a la creación de las desinencias de futuro en español (y otras lenguas romances) a partir de la perífrasis $\mathrm{HABEO}+$ infinitivo (amare habeo > amar he > amaré).

${ }^{31}$ En una ponencia no publicada titulada "Mechanisms of semantic change in grammaticalization", presentada en la Third International Cognitive Linguistic Conference, Lovaina (18-23 de julio de 1993).
} 


\subsubsection{Las motivaciones pragmáticas que están detrás de los cambios}

En lo que se refiere a la otra cuestión, se podría decir, a grandes rasgos, que lo que termina por manifestarse como una estrategia de carácter gramatical surge, paradójicamente, como efecto de necesidades ligadas al discurso, a la interacción comunicativa entre el hablante y el oyente y a la negociación del significado en el marco del contexto comunicativo. En otras palabras, "los fenómenos de gramaticalización pueden producirse directamente debido a la necesidad del hablante de ser máximamente informativo, y del oyente de ser máximamente cooperativo, dependiendo de las necesidades de la situación" (Sánchez Marco, 2008: 1819). Esto se resuelve en un enriquecimiento pragmático del significado que, al integrarse en las rutinas comunicativas, termina por hacerse convencional y, más específicamente, por formar parte del significado codificado expresado por medios gramaticales ${ }^{32}$.

Sobre los mecanismos semánticos que están detrás de estas estrategias conversacionales, se han planteado dos hipótesis principales: 1) la gramaticalización tiene origen en un proceso de carácter metafórico que proyecta los significados pertenecientes a un dominio concreto en uno de naturaleza más abstracta (Sweetser, 1990) $)^{33}, 2$ ) es el resultado de una estrategia de naturaleza metonímica basada en el principio de informatividad (Traugott y König, 1991: 191) que lleva a la convencionalización de implicaturas conversacionales, es decir, a tratar como información codificada lo que en principio no era más que una inferencia pragmática ${ }^{34}$. En el origen está la tensión que se produce entre el deseo del hablante de decir lo mínimo posible y la tendencia del oyente de enriquecer inferencialmente la información recibida del hablante (Levinson, 1987).

Una consecuencia general de esta "pragmatización” del significado sería la subjetivación del mismo, es decir, el paso de un significado objetivo basado en la situación

\footnotetext{
${ }^{32}$ En este marco, se plantea la hipótesis de la gramática emergente de P.J. Hopper (1987): la gramática está siempre en proceso de estar haciéndose.

${ }^{33}$ Por ejemplo, en el trabajo de M. J. Cuenca y M. J. Marín (2000), dedicado al estudio de ciertos verbos de percepción que acaban gramaticalizándose como conectores (a ver, vamos a ver, mira, oye y escucha), se pone precisamente de relieve que en la evolución semántica de estos verbos se pasa de un significado de percepción física (visual y auditiva) a uno vinculado a la modalización y la construcción del discurso.

${ }^{34}$ Un ejemplo de esto sería la tendencia de conjunciones con valor temporal de simultaneidad (inglés while, español mientras) a adquirir nuevos valores de carácter contrastivo-adversativo (Cuenca y Hilferty 1999: 171-174). En el ámbito de la fraseología, Ruiz Gurillo (2010: 188-193) se apoya en la “Teoría del Cambio Semántico a partir de Inferencias Asociadas" de Traugott y Dasher (2002: 35) para explicar la evolución semántica de la locución verbal cubrirse de gloria.
} 
externa a uno más subjetivo en el que aparece implicado el hablante con sus creencias y actitudes $^{35}$.

\subsection{Los usos discursivos de no me digas y los cambios ligados al "desplazamiento modal"}

Una vez esbozados los aspectos generales de la teoría de la gramaticalización, nos interesaría ver hasta qué punto los cambios formales y semánticos propios de ese proceso evolutivo tienen su reflejo en los usos discursivos de no me digas. Hay un aspecto de la evolución formal y semántica de esta expresión que nos interesa especialmente. En concreto, se trataría de considerar el grado en que tales usos son muestra de lo que se podría llamar "desplazamiento modal". Por esto entendemos el paso que se produce de la modalidad codificada a la modalidad expresada en el discurso, y el grado en que esta última, tras un proceso de recodificación, puede llegar a desplazar o desbancar a aquella. No cabe duda de que esta evolución se encuentra estrechamente unida a los procesos de fijación e idiomatización a que están sometidas estas expresiones.

Como es sabido, el punto de partida, es decir, la modalidad codificada, es la modalidad apelativa. Se trata, por tanto, de lo que se ha venido denominando una "modalidad de enunciación" ${ }^{36}$.

\subsubsection{Paso gradual en el "desplazamiento modal"}

\subsubsection{Pervivencia del valor modal apelativo}

El valor modal apelativo se mantiene plenamente activo en los usos de no me digas eso (\$ 4.1.1.) y en los anticipatorios con actitud de rechazo ( $\$ 4$ 4.2.2.). Sin embargo, contextualmente desarrollan ciertos matices modales de naturaleza expresiva y asertiva: se reacciona afectivamente ante una información que se rechaza y, sobre todo en el caso de los usos anticipatorios, se refuerza la proposición contraria al implicarse que es verdadera. $\mathrm{Si}$, además, en este último caso, se añade un componente expresivo, aparece así el

\footnotetext{
${ }^{35}$ Un ejemplo sería el paso del significado originario de may (capacidad física) al deóntico (permiso) y finalmente al epistémico (posibilidad epistémica) (Traugott, 1989). Se supone que esta evolución implica ir de un valor más objetivo a uno más subjetivo. Para una revisión crítica puede verse Berbeira Gardón (2008).

${ }^{36}$ Las modalidades de enunciación determinan la función básica del enunciado, el tipo de relación comunicativa que el hablante desea mantener con su interlocutor, y se concretan en un amplio abanico de usos pragmáticos o actos de habla.
} 
valor exclamativo tratado en $\$ 4$ 4.2.3. En todos estos usos, la modalización secundaria, aunque es ya visible, todavía no se ha impuesto a la primaria, la apelativa. Nos movemos en el plano del discurso y de las inferencias ligadas al contexto.

En consonancia con lo dicho, y visto desde la perspectiva de la fraseología, los usos indicados carecen de fijación formal y de fijación semántica, de modo que no son idiomáticos. En otras palabras, ni semántica ni formalmente hay el más mínimo rastro de gramaticalización.

\subsubsection{El valor apelativo se mantiene en estado latente}

Un paso más en este desplazamiento modal lo representa el uso descrito en $\$$ 4.1.4., por el cual el hablante muestra su incapacidad o falta de disposición a cooperar comunicativamente con el interlocutor. La hemos calificado como fórmula rutinaria semiidiomática: el valor apelativo todavía es transparente (de algún modo, el hablante le está pidiendo al interlocutor que no prosiga con su acto de enunciación debido a que él no está en condiciones de actuar de forma cooperativa). Sin embargo, ya se ha impuesto la nueva función comunicativa: el hablante muestra su falta de información, que puede ser resultado de su desconocimiento real o, más bien, de una falta de interés por el tema tratado. Desde una perspectiva formal, el grado de fijación es ya alto: no admite la presencia de un funtivo de implemento, no resulta opcional la aparición del argumento correspondiente al objeto indirecto y no puede hacerse explícito el sujeto. Por otra parte, muestra otras características que son prueba de su evolución funcional: sólo puede aparecer en el marco de una intervención, en concreto, en el comienzo de una intervención reactiva ${ }^{37}$. Su uso se circunscribe al ámbito de la interacción conversacional.

Con relación a sus orígenes, se debe tener en cuenta que este uso nace de una fórmula apelativa que se adscribe a la función instrumental del lenguaje. Se trata de influir o actuar sobre el interlocutor, de ahí que tengan una especial relevancia las motivaciones que están detrás de ese intento del hablante de imponer cierta línea de actuación a su destinatario. Todavía hoy se pueden hacer explícitas en el uso de esta fórmula: No me digas, que no tengo ni idea, No me digas, que ni lo sé ni me importa... Como resultado de un proceso de rutinización y de economía expresiva, esas motivaciones típicas y esperables, al darse por sentadas, se dejan de expresar explícitamente. Esto, sin embargo, no significa que se pierdan, sino que, precisamente por su importancia, acaban por super-

\footnotetext{
${ }^{37}$ Como respuesta a una pregunta o como continuación de una afirmación que requeriría una confirmación.
} 
ponerse al sentido apelativo original $y$, por último, terminan por desbancarlo, al menos hasta cierto punto ${ }^{38}$.

En definitiva, aunque el nivel de fijación formal alcanzado es alto (a decir verdad, la fórmula se comporta ya como una especie de marcador conversacional), el hecho de que el valor apelativo original esté todavía de algún modo presente (hemos hablado de una fórmula semiidiomática) parece sugerir que se ha alcanzado un grado medio de gramaticalización.

5.3.1.3. Desplazamiento modal ya consumado: la modalidad apelativa queda desbancada

El último peldaño en esta evolución modal lo ocuparían los usos caracterizados en $₫$ 4.1.2. y 4.1.3. (de naturaleza expresiva) y $\$$ 4.2.4.2. (refuerzo de la aserción). En estos casos se puede hablar ya claramente de un desplazamiento modal consumado: la modalidad apelativa ha sido borrada, desbancada, para imponerse otras modalizaciones alternativas que han pasado a formar parte del significado codificado. Esta evolución semántica puede describirse como el paso de una modalidad de enunciación, la apelativa, que representa un tipo de relación comunicativa básica que el hablante trata de mantener con su oyente, a una modalidad del enunciado, es decir, la expresión de cierta actitud subjetiva hacia el contenido proposicional del mensaje (se califica como algo sorprendente o como algo verdadero). Una vez más, este proceso está íntimamente unido al de fijación formal e idiomatización.

En el caso del marcador de refuerzo asertivo es fácil explicar, desde los usos anticipatorios, cómo se culmina este cambio semántico: se trataría de expresar de forma explícita lo que en los usos anticipatorios se hacía de modo implícito, esto es, apoyar una determinada proposición, presentarla como verdadera y reforzarla epistémicamente. Este proceso tendría como resultado el convertir en convencional lo que comenzó siendo una implicatura conversacional.

En lo que se refiere al uso que ya se adscribe de forma clara a la modalidad expresiva, pensamos que el punto de partida, como en el resto de casos vistos, se encuentra en el rechazo a una enunciación o, más bien, al contenido asertivo comunicado por esta. A nuestro juicio, la clave para entender la aparición de este uso se halla en el trasfondo de

\footnotetext{
${ }^{38}$ En realidad, en todo esto se percibe la prevalencia del principio de informatividad de Levinson que consiste en dar a entender el mayor número de cosas con el mínimo esfuerzo. Este mínimo esfuerzo no se ha de ver simplemente como una reducción al máximo de las palabras y expresiones utilizadas, sino también como una preferencia por las expresiones que semánticamente son más generales (Levinson, 1987: 72).
} 
informaciones contextuales que maneja el hablante y, en concreto, en el choque o contradicción que se produce entre sus expectativas -espera o desea que algo no sea ciertoy la evidencia de que realmente sí lo es. De tal choque surgiría un efecto de sorpresa, de incredulidad, que, en última instancia, sería el que terminaría por imponerse y generalizarse. De nuevo nos encontramos con que informaciones implícitas ligadas al uso de una fórmula de naturaleza apelativa acaban, no sólo por aflorar a la superficie, sino que, es más, terminan por desbancar el valor codificado que en origen les daba amparo.

Los dos últimos usos pueden considerarse el punto más alto, de los diversos valores analizados, en los procesos de fijación formal y semántica, y, por tanto, en el grado de gramaticalización alcanzado. Desde una perspectiva semántica, estamos ante expresiones plenamente idiomáticas. Formalmente, manifiestan un nivel de fijación similar al del uso anterior, aunque hay alguna peculiaridad. No me digas, cuando funciona como marcador de refuerzo asertivo, admite la incorporación de un argumento con función de sujeto (en el ejemplo 54 encontramos no me diga usted) y aparece en el nivel de la unidad monológica del acto. Posee autonomía entonativa (se expresa bajo la forma de comentario parentético) y goza de cierta movilidad en la estructura del enunciado.

Cuando actúa como marcador de modalidad expresiva, no me digas aparece en el seno de una intervención reactiva y puede constituir por sí solo acto. Se comporta ya como un genuino marcador conversacional ${ }^{39}$.

\footnotetext{
${ }^{39}$ Es cierto que este valor expresivo se da también cuando no me digas va seguido de una oración introducida por que. Semánticamente, el comportamiento de este tipo de construcción está claro: se trata de la típica estructura modalizadora en la que a un elemento de naturaleza modal (modus) le sigue otro que expresa el contenido proposicional sobre el que actúa (dictum). Ciertamente, resulta más problemático caracterizar la estructura sintáctica que hay detrás. Podría pensarse que estamos ante la siguiente posibilidad: verbo transitivo + oración sustantiva en función de implemento, como en el caso de Lamento que no te hayan admitido $\rightarrow$ Lo lamento, Lamento eso. Sin embargo, no es posible la conmutación de la supuesta oración sustantiva por un pronombre neutro en función de implemento. Tal vez se podría hablar de cierta anomalía sintáctica provocada por el carácter idiomático y fijado de la expresión, pero también podría ocurrir que estemos aquí, precisamente gracias a los procesos de fijación e idiomatización, ante un comportamiento similar al que se manifiesta en lo que son ya inequívocos marcadores conversacionales de naturaleza modal: junto a usos autónomos, presentan otros en los que van acompañados por oraciones introducidas por que en las que se retoma información ya presente en el contexto (Naturalmente que no he sido yo, Por supuesto que vamos a ir a la reunión, Claro que se lo voy a decir). Nos situaríamos, por tanto, en el ámbito de la sintaxis discursiva. Conforme a lo dicho, no se podría caracterizar estos usos expresivos de no me digas seguidos por una oración como un ejemplo de locución verbal, sino más bien como una locución marcadora (Ruiz Gurillo, 2001) con información tematizada.
} 


\subsubsection{El "desplazamiento modal" y los principios de gramaticalización}

Analizados los usos pragmáticos que en la sincronía actual presenta la construcción sintagmática no me digas, se observa que en ella, gracias a los procesos de desplazamiento modal señalados y a los cambios formales y semánticos que llevan emparejados (fijación, idiomaticidad...), conviven diferentes capas o estratos que son muestra de otras tantas fases (y recorridos alternativos) de la evolución que se está verificando en el uso discursivo de esta expresión. De acuerdo con esto, encontramos junto a los usos plenamente apelativos que se someten a las pautas formales y semánticas esperables de esa combinación sintagmática y en los que no me digas es simplemente la alternativa negativa de dime (Ahora dime / no me digas si está o no está), otros valores en los que los procesos de gramaticalización están ya avanzados (aunque no culminados), pasando por otros estadios intermedios en los que, aunque el valor apelativo sigue todavía presente y operativo, están desarrollando contextualmente nuevos valores modales (se entra en el terreno de las inferencias pragmáticas).

En todo esto parecen intervenir dos de los cinco principios de gramaticalización señalados por Hopper (1991: 22):

- Estratificación (layering): en un dominio funcional amplio están surgiendo continuamente nuevas capas. Cuando sucede esto, no se descartan necesariamente las capas más antiguas, sino que coexisten e interaccionan con las más nuevas.

- Divergencia: cuando una forma léxica se gramaticaliza hasta transformarse en un clítico o afijo, la forma léxica original puede permanecer como un elemento autónomo y sufrir los mismos cambios que los elementos léxicos normales.

Lo interesante para la evolución de no me digas es que estos principios son característicos no sólo de la gramaticalización en sus fases más avanzadas, sino también de las fases más incipientes en las que se puede plantear la cuestión de si tiene sentido o no hablar de gramaticalización (Hopper, 1991: 21).

\subsection{Gramaticalización en el discurso de no me digas: ¿un proceso de subjetivación?}

Es sabido que, en el plano semántico, uno de los cambios típicos de los procesos de gramaticalización consiste en el paso de un significado objetivo a uno subjetivo o, lo que es lo mismo, a uno en el que la implicación del hablante (con sus actitudes, puntos de vista, etc.) es mayor ${ }^{40}$. Este fenómeno de subjetivación sería una de las consecuencias

${ }^{40}$ Por ejemplo, desde luego ha desarrollado, desde su significado temporal original, valores pragmáticos de refuerzo (nivel monológico) y de acuerdo (nivel dialógico) (Alvarado Ortega y Ruiz Gurillo, 2011). 
de la pragmatización del significado. Traugott (1995: 32) lo define como "un fenómeno gradual, por el cual formas y construcciones que inicialmente expresaban, en primera instancia, significados concretos, léxicos y objetivos, llegan a realizar, a través de un uso repetido en contextos sintácticos locales, funciones progresivamente más abstractas, pragmáticas y basadas en el emisor"41.

Es evidente que en el caso que nos ocupa los valores hacia los que evoluciona no me digas se adscriben de forma inequívoca a la órbita de lo subjetivo y, más concretamente, a la expresión de actitudes subjetivas del hablante. No en vano, los diferentes usos descritos han sido clasificados como marcadores de modalidad (epistémica, asertiva y expresiva). Y es más, algunos de los usos reseñados han dado un paso más en su evolución y han acabado por convertirse en elementos de intersubjetivación o de "mediación entre hablante y oyente" (Ruiz Gurillo, 2010: 180), lo que explica que funcionen como marcadores conversacionales que aparecen en primera posición de una intervención reactiva.

Pero en todo esto hay un problema: tendría sentido hablar de subjetivación si, partiendo de un valor objetivo y concreto, se llegara a unos valores subjetivos como los vistos. Sin embargo, este no es el caso: el origen no está en un verbo decir que se limita a denotar de un modo neutro el acto de enunciación y acaba expresando nuevos significados modales de naturaleza subjetiva. Muy al contrario, lo que aquí se ha visto es cómo una forma verbal (no me digas), que ya es modal y, además, no sólo subjetiva (al implicar al hablante) sino claramente intersubjetiva (al involucrar de forma directa al oyente) evoluciona hacia otros valores modales. Por tanto, no tiene ningún sentido hablar de "subjetivación", ni siquiera de un "mayor grado de subjetivación", pues no hay forma de establecer que el origen sea menos subjetivo que el resultado. Para evitar estos problemas, aquí ha parecido más adecuado plantear la existencia de un "desplazamiento modal" o, lo que es lo mismo, el paso que se verifica desde un ámbito de la modalidad, con ciertas características formales, a otro ámbito distinto de la modalidad con otras características formales que nos aproximan al terreno de la expresión gramatical.

Evidentemente, no todo se reduce a una migración desde un territorio modal a otro territorio modal distinto. Y aunque no se puede hablar de subjetivación en el sentido de que aparezcan nuevos significados más subjetivos, es cierto que en ese paso de una modalización a otra hay también algo más. En concreto, precisamente gracias a los procesos de gramaticalización que todavía no han terminado por culminar, decir mira cada vez más a las operaciones constitutivas del discurso en el que aparece (se refuerza la orientación metadiscursiva) y se borra de forma progresiva la referencia a un acto de

\footnotetext{
${ }^{41}$ La traducción de esta cita está tomada de M. J. Cuenca y J. Hilferty (1999: 163).
} 
enunciación previo o posterior. En otras palabras, deja de contribuir al significado conceptual del enunciado para incorporarse al ámbito de las expresiones que ayudan al procesamiento de lo que se comunica (Wilson y Sperber, 1993; Blakemore, 1992: 149150). Este significado procedimental es el que determina que funcionen como operadores modales que ya afectan al conjunto de la proposición.

\section{Conclusiones}

$\mathrm{Al}$ asomarnos a la realidad del discurso, hemos podido comprobar que a partir de unos componentes básicos comunes (negación, modalidad apelativa, verbo decir, $2^{\text {a }}$ persona del singular del presente de subjuntivo) se desarrolla una amplia gama de usos diferentes, todos los cuales tienen en común el implicar cierta mirada al propio discurso en el que aparecen. Este comportamiento discursivo de la forma no me digas no es más que manifestación de un fenómeno más general: la lengua, como sistema, dispone de recursos limitados para referirse a un conjunto ilimitado de situaciones distintas. La lengua como tal no codifica todo, tan sólo una pequeña parte de lo que comunica o puede comunicar. Por tanto, ya en la propia raíz de la lengua como procedimiento semiológico está el origen de su diversidad y variabilidad.

Por otra parte, el comportamiento discursivo de la forma no me digas es un buen ejemplo de cómo lo pragmático, el uso comunicativo real ligado al contexto, al integrarse en rutinas comunicativas acaba por fijarse y, en consecuencia, a hacerse parte del código. Este, pues, no es un archivo fosilizado, inamovible, sino que se halla abierto a las presiones del uso y, en consecuencia, en constante transformación y cambio. Se cierra así un círculo en el que las pautas codificadas se convierten en realidad pragmática y sobre esta, a su vez, se construye una nueva pauta codificada relacionada con aquella de la que partía, aunque ya distinta.

En el caso concreto que nos ocupa, hemos visto que lo que en su origen era una combinatoria sintagmática de una forma verbal de modalidad apelativa con sus complementos y modificadores ha desarrollado, tras los procesos de fijación e idiomatización, diversos valores formulísticos cuyos usos pragmáticos muestran, no obstante, evidentes relaciones semánticas y formales con la expresión apelativa negativa que está en su origen. La constatación de que existen diversos grados de fijación e idiomaticidad en los usos discursivos de no me digas nos ha permitido hablar de diferentes grados de gramaticalización, así como de un paso gradual en lo que hemos llamado "desplazamiento modal" o cambio por el que la modalidad expresada en el discurso acaba desbancado a la modalidad que inicialmente se codificaba. Se ha producido de esta forma una evolución desde la modalidad apelativa original hacia otros territorios modales de 
naturaleza expresiva, epistémica y asertiva. Este desplazamiento modal ha corrido paralelo a su transformación en diversos marcadores discursivos de naturaleza modal ${ }^{42}$.

Recibido: 3-V-2011

Aceptado: 9-IX-2011

\section{Referencias bibliográficas}

Alvarado Ortega, M. B. (2010): Las fórmulas rutinarias del español: teoría y aplicaciones. Frankfurt, Peter Lang.

Alvarado Ortega, M. B. y L. Ruiz Gurillo (2011): “Un acercamiento fraseológico a desde luego", RILCE, 27-2, págs. 305-320.

Berbeira Gardón, J. L. (2008): "Hacia un estudio léxico-pragmático de la gramaticalización: convencionalización de inferencias y conceptos ad hoc". En Mora Millán, M. L. (ed.): Cognición y lenguaje: Estudios en homenaje a José Luis Guijarro Morales. Cádiz, Universidad de Cádiz, págs. 19-44.

Blakemore, D. (1992): Understanding Utterances. An Introduction to Pragmatics. Oxford-Cambridge (Massachusetts), Blackwell.

Briz, A. (2000): "Las unidades de la conversación". En Briz, A. y Grupo Val.Es.Co. (2000), págs. 51-80.

Briz, A. y Grupo Val.Es.Co. (2000): ¿Cómo se comenta un texto coloquial? Barcelona, Ariel.

Briz, A. y Grupo Val.Es.Co. (2003): "Un sistema de unidades para el estudio del lenguaje coloquial”, Oralia, 6, págs. 7-61.

Corpas, G. (1996): Manual de fraseología española. Madrid, Gredos.

Cuenca, M. J. y J. Hilferty (1999): Introducción a la lingüística cognitiva. Barcelona, Ariel.

Cuenca, M. J. y M. J. Marín (2000): "Verbos de percepción gramaticalizados como conectores. Análisis contrastivo español-catalán", Revista Española de Lingüística, volumen extra 1, págs. 215-237.

\footnotetext{
${ }^{42}$ Fuentes Rodríguez (2009: 235) ya caracteriza el no me digas expresivo como un operador modal que marca la sorpresa del hablante. Esta autora define los operadores como "unidades que se sitúan dentro del enunciado aunque no tienen ninguna función sintáctica con respecto al verbo de la oración. Afectan a un segmento de la misma, pero con una función que no apunta al elemento referencial ni introducen un actante de la acción verbal". Por el contrario, no considera el valor de refuerzo asertivo. Por su parte, $\mathrm{M}^{\mathrm{a}}$. A. Zorraquino y J. Portolés (1999) no incluyen en su nómina de marcadores del discurso estos usos de no me digas porque, cabe suponer, todavía mantienen cierta capacidad de flexión, es decir, no se ha culminado el proceso de gramaticalización.
} 
Ducrot, O. (1986): El decir y lo dicho. Polifonía de la enunciación. Barcelona, Paidós.

Fernández Bernárdez, C. (2002): Expresiones metalingüísticas con el verbo decir. A Coruña, Universidade da Coruña.

Fuentes Rodríguez, C. (2009): Diccionario de conectores y operadores del español. Madrid, Arco Libros.

Grande Alija, F. J. (1997): Las modalidades de la enunciación. León, Universidad de León (edición en formato electrónico).

Grande Alija, F. J. (2002): Aproximación a las modalidades enunciativas. León, Universidad de León.

Grande Alija, F. J. (2010): "Usos metadiscursivos de las formas exhortativas no digamos, digamos y que digamos”, Onomázein, 21, págs. 97-131.

Grice, H. P. (1975): "Logic and conversation". En Cole, P. y J. L. Morgan (eds.): Syntax and Semantics 9. Pragmatics. New York, Academic Press, págs. 41-58.

Haverkate, H. (1979): Impositive Sentences in Spanish: Theory and Description in Linguistic Pragmatics. Amsterdam, North Holland.

Hopper, P. J. (1987): “Emergent grammar”, Berkeley Linguistic Society, 13, págs. 139157.

Hopper, P. J. (1991): “On some principles of grammaticization”. En Traugott, E. C. y B. Heine (eds.): Approaches to Grammaticalization, vol. 1. Amsterdam, John Benjamins, págs. 17-35.

Hopper, P. J. y E. Traugott (1993): Grammaticalization. Cambridge, Cambridge University Press.

Levinson, S. (1987): “Minimization and conversational inference". En Verschueren, J. y M. Bertucelli-Papi (eds.): The Pragmatic Perspective. Selected Papers from the 1985 International Pragmatics Conference (Viareggio, Italy). Amsterdam/Philadelphia, John Benjamins, págs. 61-129.

Levinson, S. (1989): Pragmática. Barcelona, Teide.

Ruiz Gurillo, L. (1997): Aspectos de fraseología teórica española. Valencia, Universidad de Valencia.

Ruiz Gurillo, L. (1998): La fraseología del español coloquial. Barcelona, Ariel.

Ruiz Gurillo, L. (2000): "La fraseología”. En Briz, A. y Grupo Val.Es.Co. (2000), págs. 169-189.

Ruiz Gurillo, L. (2001): Las locuciones en español actual. Madrid, Arco/Libros.

Ruiz Gurillo, L. (2010): "Interrelaciones entre gramaticalización y fraseología", Revista de Filología Española, XC-1, págs. 173-194.

Sánchez Marco, C. (2008): "La diversidad metalingüística de la gramaticalización”. En Antonio Moreno Sandoval (ed.): Actas del VIII Congreso de Lingüística General. 
Madrid, Universidad Autónoma de Madrid, págs. 1816-1835.

Sweetser, E. E. (1990): From Etymology to Pragmatics. Metaphorical and Cultural Aspects of Semantic Structure. Cambridge, Cambridge University Press.

Traugott, E. C. (1989): "On the rise of epistemic meanings in English: an example of subjectification in semantic change”, Language, 65, págs. 31-55.

Traugott, E. C. (1995): "Subjectification in grammaticalization". En Wright, S. y D. Stein (eds.): Subjectivity and Subjectivization. Cambridge, Cambridge University Press, págs. 31-54.

Traugott, E. C. y R. B. Dasher (2002): Regularity in Semantic Change. Cambridge, Cambridge University Press.

Traugott, E. C y E. König (1991): “The semantic-pragmatics of grammaticalization revisited", en Traugott, E. C. y B. Heine (eds.): Approaches to Grammaticalization, vol. 1. Amsterdam, John Benjamins, págs. 189-218.

Wilson, D. y D. Sperber (1993): “Linguistic form and relevance”, Lingua, 90, págs. 1-25.

Zorraquino, M. A. y J. Portolés Lázaro (1999): "Los marcadores del discurso". En Bosque, I. y V. Demonte (dirs.): Gramática descriptiva de la lengua española 3. Madrid, Espasa-Calpe, págs. 4051-4213.

\section{Procedencia de los ejemplos}

Berman, S. (2004): "La grieta”, Puro teatro. México, FCE, págs. 121-180.

Briz, A. (coord.) (1995): La conversación coloquial (Materiales para su estudio). Valencia: anejo XVI de Cuadernos de Filología.

Ramoneda, J. (2009): “La soledad del presidente”, El País Domingo (15-3-09), pág. 12.

REAL ACADEMIA ESPAÑola. Corpus de referencia del español actual (CREA): http://www.rae. (15-2-2011).

Ruiz Zafón, C. (2003): La sombra del viento. Barcelona, Editorial Planeta.

Ruiz Zafón, C. (2008): El juego del ángel. Barcelona, Editorial Planeta. 